\title{
De lo devoto a lo profano. El comercio y la producción de libros en el Valle Central de Costa Rica (1750-1850)
}

\author{
Por Iván Molina
}

El 22 de enero de 1858, la librería de la imprenta "El Album", ubicada en San José, publicó un aviso en el Album Semanal, periódico editado por la misma casa impresora, en el que ofrecía un variado espectro de productos: papeles, cintas, plumas, pizarras, lápices, lacre, tinteros, tinta y otros. El anuncio concluía con un extenso catálogo de las obras en venta, cuyo título empezaba con la letra " $\mathrm{A}$ "; en ulteriores números del diario, el listado se completól. ¿Por qué se editó tal lista? El tráfico de libros en el Valle Central, ¿era ya tan significativo que valía la pena promocionarlo específicamente?

\section{I. ¿QUÉ SE LEÍA EN UNA COLONIA MARGINAL?}

. La edición del catálogo evidencia, sin duda, una variación clave: un siglo atrás, el libro era un artículo escaso y comercialmente poco atractivo. El texto típico durante la colonia era casi siempre de origen español y de carácter devoto y vulgarizador: catones, cartillas, breviarios, novenas y catecismos. ¿Faltaban las obras profanas

$\therefore$ La investigación que sirvió de base para este artículo fue financiada por la Universidad de Costa Rica. El autor agradece la colaboración de Virginia Mora, Anthony Goebel y Paulina Malavassi en la recolección de los datos. Una primera versión de este trabajo fue leída por Steven Palmer, Victor Hugo Acuña y Arturo Taracena, cuyos comentarios contribuyeron a mejorarlo.

i) Album Semanal (San José), enero 22 a marzo 13, 1858, p. 4. Cartago fue la capital de Costa Rica hasta 1823; a partir de ese año, lo fue San José. 
y extranjeras? El volumen piadoso, que prevalecía en las exiguas bibliotecas privadas, dejaba espacio - aunque poco - para poemarios, novelas, dramas y ensayos sobre comercio, filosofía y moral, política, derecho, medicina, geografía e historia ${ }^{2}$.

La producción de Calderón de la Barca, Loyola y Quevedo coexistía con la de La Fontaine, Bossuet, Racine y Kempis, cuya - atribuida - Imitación de Cristo figuraba casi siempre en las bibliotecas de los más acaudalados. La Ilustración se conocía, como en otras áreas coloniales ${ }^{3}$, a través de los trabajos de sus difusores ibéricos y criollos: el benedictino español Benito Jerónimo Feijó y el dominico mexicano Fray Servando Teresa de Mier; y gracias a escritos vulgarizadores o adversos: Armonia de la razón y la religión, de la pluma de Teodoro de Almeyda, y la Impugnación a Voltaire, de Mousso.

El libro prohibido, en contraste con Nueva España o Guatemala ${ }^{4}$, circulaba poco; a lo sumo, se le entreveía en los interdictos que enviaba el Santo Oficio o que aparecían en cédulas reales 5 . Los únicos títulos sospechosos, avaluados en los inventarios sucesorios de fines de la

${ }^{2}$ Iván Molina, "Libros de comerciantes y campesinos del Valle Central de Costa Rica (1821-1824)": Revista de Filosofia, 24:59 (junio 1986), pp. 137-154. Gilberth Acuña, Francisco Alvarez y Marta Morera, "La literatura que circulaba en Cartago y San José (1800-1820)": Avances de Investigación del CSUCA, 41 (septiembre 1988), pp. 1-43. Amaldo Moya, Comerciantes y damas principales de Cartago (1750-1820). La estructura familiar y el marco material de la vida cotidiana (M. A. diss., Universidad de Costa Rica, 1991), pp. 24.5-331.

${ }^{3}$ Los clásicos sobre el tema son John T. Lanning, The Eighteenth-Century Enlightenment in the University of San Carlos de Guatemala (Cornell 1956) y Arthur P. Whitaker (ed.), Latin America and the Enlightenment (Comell 1963). Véase también: John T. Lanning, Academic culture in the Spanish colonies (Durham 1940), pp. 61-89 y Mariano Picón Salas, A cultural history of Spanish America (Berkeley 1962), pp. 129-175. Para un enfoque más reciente, véase: José Carlos Chiaramonte, La crítica ilustrada de la realidad (Buenos Aires 1982), pp. 133-178 y La llustración en el Río de la Plata (Buenos Aires 1989), pp. 11-116. La obra de Feijoó y de otros difusores extendió a la vez que desradicalizó el ideario ilustrado.

4 José Abel Ramos Soriano, "Los orígenes de la literatura prohibida en la Nucva España en el siglo XVIII": Historias, 6 (1985) pp. 25-47 y "Una senda de la perversión en el siglo XVIII: el imaginario erótico en la literatura prohibida en Nueva España": Scrgio Ortega (ed.), De la santidad a la perversión (México 1986), pp.69-90. Jorge Mario García Laguardia, Precursores ideológicos de la Independencia en Centreamérica. Los libros prohibidos (Guatemala 1969).

${ }^{5}$ Luis Felipe González Flores, Evolución de la instrucción pública en Costa Rica (San José 1978), pp. 23-24. Ramón Salazar. Historia del desenvolvimiento intelectual de Guatemala, vol. 2 (Guatemula 1951), pp. 183-184. 
colonia $^{6}$, fueron Mística ciudad de Dios de Sor María de Jesús de Agreda, El año cristiano de Jean Croisset, Medicina casera de Buchan y un texto "... que trata de los fracmasones ...", cuyo dueño (con una fortuna de 3,829 pesos) era Julián Azofeifa y Madrid, un vecino de Cartago, muerto en febrero de 1782 .

El diferenciado acceso a las obras se vislumbra sin esfuerzo en el Cuadro 1: entre los bienes de campesinos y artesanos, el libro era una verdadera excepción; de figurar a la par de utensilios, enseres y muebles, se trataba - en su mayoría - de títulos devotos. El productor directo era, a lo más, propietario de vulgarizadores, del tipo Despertador cristiano eucarístico, del español José Barcia y Zambrana; volúmenes de bajo precio, viejos y a veces truncos. El ejemplo de Juan Rodríguez, agricultor y vecino de Heredia, es elocuente: al fallecer en mayo de 1822 , su caudal ascendía a 474 pesos, suma que incluía el valor de ".... un dispertador [sic] eucarístico en dies reales, un libro viejo doctrinal ya sin título en doce reales, un Caton viejo en medio real y un catecismo Ripalda en real y medio ..."8

6 Para una crítica de los inventarios sucesorios como fuente para la historia cultural, véase: Jacques Queniart, " $L$ 'utilisation des inventaires en histoire socio-culturelle": Les Actes Notariés. Source de l' histoire sociale XVIe-XIXe siecles (Estrasburgo 1979), p. 120. Bartolomé Bennassar, "Los inventarios post-mortem y la historia de las mentalidades": La documentación notarial y la historia, vol. 2 (Salamanca 1984), pp. 139-146.

7 Archivo Nacional de Costa Rica (en adelante ANCR), Mortuales Coloniales (en ádelante MC), Cartago (en adelante C), exp. 512 (1804), f. 22 . El caso de Místira ciudad de Dios se analiza con detalle en Antonio Márquez, Liseratura e Inquisición en España (1478-1834) (Madrid 1980), pp. 91-93. El Indice de 1790 enlista en la categoría de prohibidos los libros de Croisset y Buchan. Irving A. Leonard, "A frontier library, 1799": Hispanic American Historical Review, XXIII (1943), pp. 28-29. Para una contextualización de la obra de Buchan, véase: Roy Porter, "A touch of danger: the man midwife as sexual predator": G. S. Rousseau y R. Porter (eds.), Sexual underworlds of the Enlightenment (Chapel Hill 1988), pp. 206-232.

${ }^{\$}$ ANCR, Mọruales Independientes (en adelante MI), Heredia (en adelante H), exp. 2612 (1822), f. 3. Tódo paréntesis así [] es mío. El período cubierto por los cuadros 1 y 2 está condicionado por las investigaciones previas de Molina, "Libros de comerciantes", pp. 137-154 y de Acuña, Morera y Alvarez, "La literatura que circulaba", pp. 1-43. Los datos de Moya, en Comerciantes y clamas principales, no se pudieron sintetizar con los anteriores, ya que este autor utilizó un sistema distinto de clasificación. Esto explica que la fecha inicial sea 1800 (y no 1750) y la final 1824 (y no 1821, cuando Costa Rica se independizó de España). Los cuadros citados, se basan en una revisión de 136 inventarios sucesorios de Carago, 236 de San José, 27 de Heredia y 34 de Alajuela; del total de casos (433), sólo se registraron libros en 87. 


\section{CUADRO 1}

Distribución de 736 volúmenes, con un valor de 1,712 pesos, registrados en 87 inventarios sucesorios efectuados en el Valle Central (1800-1824)

\begin{tabular}{rccllrr}
\hline $\begin{array}{l}\text { Nivel de } \\
\text { fortuna } \\
\text { en pesos }\end{array}$ & $\begin{array}{l}\text { \% de inven- Promedio de } \\
\text { tarios con } \\
\text { libros }\end{array}$ & $\begin{array}{l}\text { Valor } \\
\text { volúmenes } \\
\text { por caso }\end{array}$ & $\begin{array}{l}\text { promedio } \\
\text { en pesos } \\
\text { y reales }\end{array}$ & $\begin{array}{l}\text { Valor por } \\
\text { por unidad } \\
\text { en pesos }\end{array}$ & $\begin{array}{l}\text { Volú- } \\
\text { menes }\end{array}$ & \% \\
\hline-199 & 4.5 & 1.7 & 0.7 & -1 & 221 & 30.0 \\
$200-499$ & 11.9 & 2.3 & 0.6 & $1-2$ & 357 & 48.5 \\
$500-999$ & 29.9 & 2.7 & 1.1 & $3-4$ & 69 & 9.4 \\
$1,000-1,999$ & 22.6 & 5.7 & 1.7 & $5-6$ & 38 & 5.2 \\
$2,000-4,999$ & 33.3 & 12.4 & 2.0 & $7-8$ & 20 & 2.7 \\
$5,000-9,999$ & 60.0 & 12.9 & 3.2 & $9-10$ & 6 & 0.8 \\
10,000 y más & 87.5 & 45.0 & 2.6 & 11 y más & 19 & 2.6 \\
& & & & Desconocido & 6 & 0.8 \\
\hline Total & 20.1 & 8.4 & 2.2 & Total & 736 & 100.0 \\
\hline
\end{tabular}

a. Volúmenes $=$ tomos + ejemplares de un mismo título.

Fuente: Molina, "Libros de comerciantes", pp. 137-154. Acuña, Morera y Alvarez, "La literatura que circulaba", pp. 1-43.

El caso de Rodníguez, dueño de 4 obras valoradas en 3 pesos, se ubicaba por encima del promedio: en los patrimonios por debajo de los 500 pesos, el libro era casi un completo extraño. ¿Extendido analfabetismo? El sistema escolar, ínfimo y desorganizado9, difícilmente contribuía a la difusión de los impresos, cuyo precio tampoco era un estímulo: aunque la cotización de catecismos y cartillas oscilaba entre 0.2 y 0.4 reales, el valor de los textos era - usualmente - superior a un peso. La suma era considerable: en 1821, el jornal de un peón ascendía de 3 a 5 pesos al mes; pero un machete valía 0.6 reales, un telar 3 pesos, un arado 2 pesos, una vaca 6 pesos y una mula más de 12 pesos $^{10}$.

\footnotetext{
${ }^{9}$ González Flores, op. cit., pp. 111-115.

11) Los precios los tomé de los inventarios sucesorios del año 1821. Los datos sobre sueldos son fragmentarios. Lowell Gudmundson, Estratificación socio-racial y económica de Costa Rica (1700-1850) (San José 1978), pp. 98-102. Iván Molina, "Dos viajes del "Jesús María' a Panamá": Revista de Ciencias Sociales, 30 (diciembre 1986), p. 117.
} 
El alto precio de las obras obedecía a varios factores: los elevados costos con que operaba la producción editorial europea y americana, derivados de una tecnología todavía primitiva, dependiente del trabajo manual y afectada por la escasez de papel y de tinta ${ }^{11}$; la ausencia de imprentas en el Valle Central - la primera se trajo en 1830 -, lo que obligaba a importar todos los textos, en especial de España, Guatemala y México; y el libro, en el tráfico colonial, era otro efecto de comercio más y, pese a su ínfimo consumo, cayó en las redes del intercambio desigual, que prevalecía en el Nuevo Mundo ${ }^{12}$.

El acceso a los libros exa evidentemente más amplio entre los sectores acaudalados del Valle Central: comerciantes, terratenientes, burocratas y curas; con bibliotecas superiores en promedio a la docena de textos, se podían ufanar de poseer obras bastante caras. El precio de ciertos ejemplares, a veces en extremo elevado, obedecía a sus atributos físicos: tamaño, excelencia tipográfica, tipo de papel y empaste. El exportador de San José, José Ana Jiménez, expiró - al igual que Juan Rodríguez + en mayo de 1822; dueño de una fortuna de 19,597 pesos, disponía de 15 títulos en 36 volúmenes, cuyo valor total superaba los 86 pesos. Las joyas de su colección eran "... la obra del año Christiano de dies y ocho tomos en plata en cincuenta pesos, otra María del Alma en quatro tomos plata en dies y seis ..."13

¿Atesoramiento? El libro, en un contexto en esencia agrario y oral, era de por sí símbolo de prestigio: el dueño de un texto, aunque se tratara simplemente de un catecismo trunco, se acercaba a una cultura escrita, exclusiva y exigua, asociada con el poder y la riqueza ${ }^{14}$. La obra

"Robert Darnton, The business of Enlightenment (Harvard 1979), pp. 177-245. Lucien Febvre y Henri-Jean Martin, L'apparition du livre (Paris 1958). Svend Dahl, Historia del libro (Madrid 1972). José Toribio Medina, Historia de la imprenta en los antiguos dominios españoles de América y Oceanla (Santiago 1958).

${ }_{12}$ Los estudios sobre los comerciantes y el capital comercial en la Hispanoamérica del siglo XVIII son abundantes. Carlos Sempat Assadourian, El sistema de la eiconomia colonial (México 1983); Juan Carlos Garavaglia, Mercado interno y economía colonial (México 1984); José Carlos Chiaramonte, Formas de sociedad y ecunomía en Hispanoamérica (México 1984); Tray S. Floyd, "The Guatemala merchants. the Government, and the "Provincianos', 1750-1800": Hispanic American Historical Review, 41:1 (February 1965), pp. 90-110; Víctor Hugo Acuña, "Capital comercial y comercio exterior en América Central durante el siglo XVIII: una conlribución": Estudios Sociales Centroamericanos, 26 (mayo 1980), pp. 71-102.

13 ANCR, MI, San José (en adelante SJ), exp. 705 (1822), f. 12.

14 El complejo problema de los vínculos entre la cultura escrita y la oral se analiza en R. A. Houston, Literacy in early modern Europe. Culture und education 1500-1800 (Londres 1988), pp. 218-229. 
de lujo, sin embargo, servía a la vez para otros propósitos: ostentación y ahorro. El último era vital, dada la falta de liquidez prevaleciente de Nueva España a Buenos Aires ${ }^{15}$. El Año cristiano de Jean Croisset era una pieza a la altura de las vajillas de plata, los candelabros de bronce, los collares de perlas y la imaginería preciosa: en un apuro financiero, se convertía en un tesoro enajenable ${ }^{16}$.

\section{CUADRO 2}

Tamaño y temática de 87 bibliotecas privadas del Valle Central (1800-1824)

\begin{tabular}{|c|c|c|c|c|c|c|c|c|}
\hline Títulos & $\begin{array}{l}\text { Biblio- } \\
\text { tecas }^{\mathrm{a}}\end{array}$ & - & $\begin{array}{l}\text { Volú- } \\
\text { menes }\end{array}$ & $\begin{array}{l}\text { Biblio- } \\
\text { tecas }^{\mathrm{a}}\end{array}$ & $\%$ & Temática & $\begin{array}{l}\text { Volú- } \\
\text { menes }\end{array}$ & $\%$ \\
\hline 1 & 24 & 27.6 & 1 & 20 & 23,0 & Religión & 402 & 54.6 \\
\hline $2-4$ & 33 & 37.9 & $2-4$ & 36 & 41.4 & Gramática & 64 & 8.7 \\
\hline $5-9$ & 17 & 19.5 & $5-9$ & 13 & 14.9 & Derecho & 49 & 6.3 \\
\hline $10-19$ & 8 & 9.2 & $10-19$ & 11 & 12.6 & Literatura & 45 & 6.1 \\
\hline \multirow[t]{8}{*}{$20-49$} & 5 & 5.8 & $20-49$ & 4 & 4.6 & Filosofía & 38 & 5.2 \\
\hline & & & $50-99$ & 2 & 2.3 & Historia & 30 & 4.5 \\
\hline & & & 100 y más & 1 & 1.2 & Política & 13 & 1.8 \\
\hline & & & & & & Ciencias & 12 & 1.6 \\
\hline & & & & & & Geografía & 6 & 0.8 \\
\hline & & & & & & Economía & 5 & 0.7 \\
\hline & & & & & & Otros & 14 & 1.9 \\
\hline & & & & & & Desconocido & 58 & 7.8 \\
\hline Total & 87 & 100.0 & Total & 87 & 100.0 & Total & 736 & 100.0 \\
\hline
\end{tabular}

a. La diferencia en la distribución de las bibliotecas según "lítulos" y "volúmenes" obedece a que algunos títulos se componían de varios tomos, y de otros, el propietario poseía más de un ejemplar.

Fuente: La misma del Cuadro 1 .

La colección de Jiménez, aunque pequeña en comparación con otras, era digna de un exportador: tres docenas de volúmenes, caros y títulos de variada temática. El impreso pío y vulgarizador no faltaba

15 John Lynch, Las revoluciones hispanoamericanas 1808-1826 (Barcelona 1980) p. 22. David Brading, Mineros y comerciantes en el México borbónico (1763-1810) (México 1975), pp. 135-178. Iván Molina, La alborada del capitalismo agrario en Costa Rica (San José 1988), pp. 17-59.

is Moya, op. cit., pp. 140-244. 
en su vivienda, pero competía con otras obras, de carácter profano. El Cuadro 2 detalla el peso de tales textos, que distinguían a las bibliotecas eminentes: entre otros, España sagrada de Flores, Historia antigua de Commynes, Sueños morales de Torres, Política indiana de Solórzano, la Curia filípica de Hevia Bolaños y Teórica y práctica de comercio y marina de Ustáriz ${ }^{17}$.

El contraste entre los textos eruditos, característicos de las casas de los pudientes, y los vulgarizadores, típicos de campesinos y artesanos, evidencia un consumo que, en cuanto a los tópicos tratados, se diferenciaba ya socialmente. ¿Mundos culturales del todo aparte? Ana Josefa Rojas, viuda de José Antonio García, agricultor de San José, diría que no sin vacilar; dueña de un caudal de 867 pesos, al morir en diciembre de 1815 poseía, entre otros,

- : "un libro bueno Buchan de medicina en cuatro pesos. Otro tomo de Feijo en un peso. Otro idem biejo en cuatro rales. Otro tomo de medisina Florilegio en cuatro reales ... Otros dos tomos de Febrero en ocho reales cada uno. Otro idem de sirugia en 3 pesos ... Otro pequeño de medisina su autor Dr. Manuel Fermandez en cuatro reales ..."18

La experiencia de Rojas precisa los umbrales de tal universo bibliográfico: a partir de un trasfondo común - cartillas, catones, breviarios -, se erigía un acceso desigual a los libros, según su valor y temática. La diferenciación cultural, con todo, era limitada: quizá un campesino o artesano, por gusto o por azar, disponía de un volumen de Feijoó entre sus bienes; pero esto difícilmente lo convertiría en otro Menocchio ${ }^{19}$. El caso del lector acaudalado era parecido: en su estantería, el impreso profano que figuraba era tradicional y conservador; jamás una pieza erótica, libertina o pornográfica ${ }^{20}$.

${ }^{17}$ Las obras citadas aparecen en los inventarios sucesorios de vecinos principales del Valle Central fallecidos entre 1750 y 1824. Molina, "Libros de comerciantes", pp. 137-154; Acuña, Morera y Alvarez, op. cit; Moya, op. cit., pp. 245-331. Los textos de Solorzano, Hevia Bolaños y Ustáriz figuran también en una lista de libros propuesta para formar la biblioteca del Consulado de Comercio de Veracruz. Irving Leonard y Robert Smith, "A proposed library for the Merchant Guild of Veracruz, 1801": Hispanic American Historical Review, XXIV (1944), pp. 84-102.

18 ANCR, MCSJ, exp. 332 (1815), ff. 12-12 v.

19 Carlo Ginzburg, II formaggio e i vermi: il cosmo di un mugnaio del '500 (Turín 1976).

${ }^{20}$ Este tipo de literatura suele jugar un importante papel político. Véase: Roger Damton, The literary underground of the Old Regime (Harvard 1982), pp. 182-208; Ian McCalman, Radical underworld. Prophets, revolutionaries and pornographers in London, 1795-1840 (Cambridge 1988), pp. 204-231; Antoine Baecque, "Pamphlets: Libel and political mythology": Robert Damton y Daniel Roche (eds.), Revolution in print (Berkeley 1989), pp. 165-176. 
El texto que circulaba en el ocaso colonial, selecto o vulgarizador, no era un agente que desafiara el orden establecido: en su conjunto, las obras difundían una visión del mundo española y católica; del Liberalismo, la Masonería y las Luces, se ofrecía - a lo sumo - un enfoque desvirtuado. ¿Límites cualitativos? La cultura libresca del Valle Central los tenía, sin duda; pero tampoco carecía de topes cuantitativos. Las cifras son claras: de 433 inventarios de los años 1800-1824, aparecen libros en 87 únicamente; y los 736 volúmenes avaluados (en 1,712 pesos) correspondían a 335 títulos distintos ${ }^{21}$.

La distribución de las bibliotecas según su tamaño, trazada por el Cuadro 2, especifica otros detalles: en un 23 por ciento de los inventarios, se disponía apenas de un texto, ninguno alcanzaba los 50 títulos y sólo uno superaba los 100 volúmenes, el de Pedro Antonio Solares. Este español era, en los últimos años de la colonia, el comerciante de más peso en el tráfico de libros: oriundo de Asturias, se casó a fines de 1797 con Casimira Sandoval, vecina de Heredia; al morir la pareja, en marzo de 1824 , la fortuna de la familia ascendía a 84,724 pesos. El desglose de sus bienes contabilizó, entre otros, “... dos docenas [de] catecismos a tres reales [cada uno y] veinte y cinco cartillas a un real [cada una] ..."22

El exiguo tamaño de las bibliotecas se patentiza en el caso de Solares: con sus 36 títulos y 119 volúmenes - valorados en 162 pesos -, era una de las más extensas del país. La escasez cuantitativa iba a la par de la pobreza temática: en los estantes de un vecino principal, se alineaba un cuerpo de obras diversas por sus tópicos, precios, categoría y formato; pero se carecía de colecciones especializadas. ¿A qué obedecía tal ausencia? El Valle Central era un territorio intelectualmente pobre, pese a distinguidas excepciones: Antonio Liendo y Goiecoechea, docente en Guatemala; Florencio del Castillo, Presidente de las Cortes de Cádiz y luego Obispo de Oaxaca; y José María Zamora, abogado y escritor en España ${ }^{23}$.

El alza económica y demográfica, experimentada tras 1750 , se caracterizó por tres procesos básicos: colonización agrícola, auge del comercio y cierto despliegue urbano. El crecimiento, sin embargo, fue

${ }^{21}$ Molina, "Libros de comerciantes", pp. 137-154; Acuña, Morera y Alvarez, op. cit., p. $1-43$.

22 ANCR, MIH, exp. 2889 (1824), f. 26.

${ }^{23}$ González Flores, op. cit., pp. 62-68, 72-73 y 134-168. Los tres personajes citados, oriundos de Cartago, jamás volvieron a Costa Rica. 
de tipo extensivo, sin cambios tecnológicos de peso: en 1821, Costa Rica, con sus 60,000 almas, eia una colonia marginal del agonizante imperio español. La estructura artesanal era diminuta y atrasada y el tráfico exterior dependía, en esencia, de las plazas de Nicaragua y Panamá. El excedente agrícola, producido por campesinos mestizos y libres - con un acceso diferenciado a la tierra -, era extraído por los comerciantes (a la vez propietarios de extensos terrenos y ocupantes de cargos públicos), a partir del intercambio desigual ${ }^{24}$.

La baja división del trabajo se evidenciaba en todos los campos: en un mundo básicamente agrario, el artesano era todavía un campesino y el sacerdote unía el oficio de pastor con el de comerciante y prestamista. La estructura económica, cuyo eje era la producción familiar orientada a la subsistencia, ofrecía poco espacio para la diversificación ocupacional: en los últimos días de la colonia, tras 70 años de crecimiento, se carecía aún de capas de abogados, médicos, docentes y boticarios. La ausencia de tales profesionales, en otras partes dueños de bibliotecas más laicas y especializadas ${ }^{25}$, brillaba en un entramado cultural gris, devoto, tradicional y provinciano.

i. El crecimiento - cuantitativo y cualitativo - del tráfico de obras enfrentó, en el Valle Central, variados factores adversos: la penuria demográfica, la escasa organización escolar y una atmósfera intelectualmente pobre. ¿Y la Inquisición? El ojo avizor del Santo Oficio, en la práctica, era casi innecesario: únicamente por desinterés y rechazo - normales en un ambiente tan conservador - se explica la escasez de libros prohibidos en las bibliotecas de la época. El tránsito del siglo XVIII al XIX se distinguió, en España y su imperio, por una exitosa difusión de los textos interdictos, dado el ocaso inquisitorial ${ }^{26}$.

\footnotetext{
${ }^{24}$ Iván Molina, Costa Rica (1800-1850). El legado colonial y la génesis del capitalismo (San José 1991), pp. 19-178. El crecimiento económico posterior a 1750 fue generalizado en toda Hispanoamérica. Ciro Cardoso y Héctor Pérez, Historia económica de América Latina, vol. 2 (Barcelona 1979), pp. 9-14. El dominio del capital comercial y los diversificados intereses de los comerciantes eran otros rasgos comunes en el Nuevo Mundo. Brading, op. cit., pp. 135-178; Doris Ladd, The Mexican nobility at independence, 1780-1826 (Austin 1976), p. 164.

${ }^{25}$ Maxine Chevalier, Lectura y lectores en la España de los siglos XVI y XVII (Madrid 1976), pp. 13-48. Juan Eloy Gelabert, "La cultura libresca de una ciudad provincial del Renacimiento": La documentación notarial y la historia, vol. 2, pp. 147-163. Carlos Alvarez, "Adoctrinamiento y devoción en las bibliotecas sevillanas del siglo XVIII": $L a$ religiosidad popular, vol. 2 (Barcelona 1989), pp. 23-28.

${ }_{26}$ Jean Pierre Dedieu, "El modelo religioso: rechazo de la reforma y control del pensamiento": Bartolomé Bennassar (ed.), Inquisición española: poder político y control
} 
El espectro de libros, víctima de tales estrecheces, exhibía un cierto estancamiento: de 23 escritores cuyas fechas vitales se conocen - con excepción de los clásicos griegos y romanos -, sólo tres nacieron en el siglo XVIII; y de los títulos existentes, un significativo número se editó antes de $1750^{27}$. La actualización era difícil sin duda; en un contexto de importación esporádica, a raíz del bajo consumo, se basó en los volúmenes traídos por los emigrantes. Los dueños de los textos más recientes eran varios comerciantes de origen foráneo: Solares, Núñez del Arco, Marchena y Mata ${ }^{28}$.

La pequeñez del comercio de obras convirtió a los procesos hereditarios en las principales vías de transmisión: tras el óbito, ciertos ejemplares se podían vender o ceder para cancelar las deudas del difunto, las costas del inventario y los gastos del entierro. La práctica que prevalecía, sin embargo, era la de distribuir los textos entre los herederos, a veces analfabetos. El caso de José Ana Jiménez es, otra vez, útil: su colección se dividió entre su viuda, tres hijas y un hijo; pero el único que sabía firmar era el varón, cuya adjudicación - un par de volúmenes - fue curiosamente la más baja ${ }^{29}$.

¿Descuido de los albaceas? El desvelo de los ejecutores era que el cuerpo de bienes de cada hijuela fuera de igual valor. La división de las obras se efectuaba sin importar las destrezas culturales de sus futuros dueños; por esta vía, el libro podía descender, en silencio, por las jerarquías sociales: entre las parejas estériles y los solteros - en especial los curas -, se solía heredar a los parientes pobres, a los sirvientes y a los esclavos de uno y otro sexo, rara vez alfabetizados. Maximiliano Alvarado y Girón, presbítero y vecino de Cartago, testó en enero de 1779 y dejó sus bienes (en cuenta 28 volúmenes) a su hermana Ana Rita, esposa de Faustino Ugalde, una pareja analfabeta ${ }^{30}$.

La existencia de libros entro los bienes de otras familias. traza el alcance de su difusión. Dominga Solano, esclava, casó en segundas

social (Barcelona 1984), pp. 253-262. Virgilio Pinto, "La censura: sistemas de control e instrumentos de acción": Angel Alcalá (ed.), Inquisición española y mentalidad inquisitorial (Barcelona 1984), pp. 269-287. Márquez, op. cit., pp. 217-230. Richard Konetzke, América Latina. La época colonial (México 1979), p. 262. Guillermo Céspedes del Castillo, América Hispónica (1492-1898) (Barcelona 1985), pp. 401-407.

${ }_{2 J}$ Molina, "Libros de comerciantes", p. 154.

${ }^{28}$ ANCR, MCC, exps. 1022 (1821) y 1036 (1821). MI.C, exp. 1211 (1824). MI.H., exp. 2889 (1824).

29 ANCR, MISJ, exp. 705 (1822), ff. 53-59.

${ }^{30}$ ANCR, MCC, exp. 496 (1780), ff. 1-26. 
nupcias con el esclavo Seferino Luna; tras varios años, ahorraron lo suficiente para comprar su libertad y la de dos de sus tres hijos. La esposa falleció en 1818; en julio de 1822, tras el inventario, el pátrimonio ascendía a 394 pesos, valor de una vivienda, un cerco, un potrero, dos caballos, dos yeguas, joyas, un molde para fabricar candelas, utensilios de carpintería y varios textos: "... un catecismo en un real ... un librito de San José en dos reales ... un arte usado en ocho reales ..."31

El adjudicatario - analfabeto - de un volumen quizá trataría de venderlo, pero lo más seguro era que lo dejara aquí o allá, dentro de un baúl o encima de un aparador. La obra, tras la muerte del propietario, volvería a circular, con igual o superior fortuna; ciclo que contribuía a perpetuar el prevaleciente entramado bibliográfico. Ei traspaso de los libros los desgastaba físicamente, ora por el uso, ora por el desuso; deterioro que se trasluce en los principales adjetivos con que se calificó a los textos en los inventarios sucesorios: "usado", "trunco", "maltratado", "viejo" y .descuadernado".

El préstamo de obras era otra práctica que las difundía y las desgastaba. La colección del difunto Julián Azofeifa y Madrid, en septiembre de 1779, estaba en la vivienda de su albacea, Fermín Mondragón; 25 años después, en diciembre de 1804, Luz Pacheco, viuda de este último, declaraba que su esposo le entregó, entre otros bienes, un volumen cuyo

y. « ... titulo parese era la Recopilacion de Indias, la qual la havia prestado dicho señor !il: vicario [Antonio Azofeifa y Madrid, hermano de Jultán] a don Joaquín Oreamuno, y 1.1. de este paso a poder de Don Tomas Alvarado, de quien lo percivio su hijo politico Don Geronimo Escarpeta en cuyo poder para en el día..."32

El avalúo y la división de los bienes de un difunto, que permitía recuperár lo prestado, era una ocasión propicia para adquirir obras en condiciones ventajosas. El sacerdote Juan Manuel Casasola, vecino de Cârtago, murió en abril de 1783; un mes después, el patrimonio del eclesiástico, que ascendía a 1,736 pesos, se subastó públicamente. La almoneda fue aprovechada por José Antonio García para comprar, entre otrás cosas, ". . las dos vidas del padre Margil por las dos tercias partes de su abaluo [seis pesos] que son cuatro pesos"33.

ANCR, MIC, exp. 2997 (1822), f. 7.

.1. 32 ANCR, MCC, exp. 512 (1804), ff. 393-393 v.

23. ANCR, MCC, exp. 664 (1783), f. 37. Este José Antonio García no era el mismo que se citó previamente. 
El deterioro físico de los textos, tan perjudicial para su valor, se derivaba casi siempre de un almacenaje pésimo. El presbítero cartaginés, José Antonio de Alvarado, al testar en abril de 1796, declaró que conservaba sus obras en una "librería"34; en cambio, en la Iglesia del Convento de Orosi, una comunidad indígena al sureste de Cartago, la biblioteca se instaló en un

“... cuartito ... en que se ... guardan tercios de sal, vegigas de manteca, lonjas de marrano, piezas de carne, trastes viejos y tantas inmundicias que causa asco entrar en él ..."35

El descuido con que se trató a los impresos en Orosi es otro indicador de la cultura del libro prevaleciente en el Valle Central; pero ésta, con sus obvios umbrales cuantitativos y cualitativos, no difería en exceso de lo que era común en diversos casos americanos y europeos ${ }^{36}$. El perfil básico es visible sin esfuerzo: entre el vulgo, un consumo de textos devotos, de escaso valor y pocas páginas por unidad; y según se ascendía por la escala social, en bibliotecas con más volúmenes que títulos, un acceso ampliado a obras más caras y seculares, cuya variada temática era extraña en un entomo campesino o artesano.

\footnotetext{
${ }^{34}$ ANCR, Protocolos Coloniales (en adelante PC), C, exp. 453 (1796), f. 8 v. "Librería" significa aquí estantería.

${ }^{35}$ ANCR, Municipal, SJ, exp. 319 (1830), f. 1. Agradezco a la profesora Patricia Vega la localización de este documento, que fue escrito por el bachiller Rafael Francisco Osejo, ex-Rector de la Casa de Enseñanza de Santo Tomás, en octubre de 1830. Osejo aseveraba que en 1817 la biblioteca, compuesta por tres biblias, varias obras de Bossuet y de otros autores y "... muchos manuscritos ..." todavía se encontraba en buen estado. El Jefe Político de Cartago, José María Peralta, atribuía (un mes más tarde) el deterioro de la biblioteca a que la lgiesia fue abandonada por su administrador, Aniceto Cortés, y qued6 a merced de los indígenas. Ibidem, f. 3. Los dos quejosos pedfan que los libros sobrevivientes se trasladaran al claustro tomasino, lo que se hizo poco tiempo después.

36 Natalie Z. Davis, Sociery and culture in early Modern France (Stanford 1975), pp. 189-226. Peter Burke, Popular culture in early Modern Europe (New York 1978), pp. 250-259. Margaret Spufford, Small books and pleasant histories (Cambridge 1981), pp. 129-155. Roger Chartier, Cultural history. Between practices and representations (Ithaca, N.Y. 1988), pp. 151-171. Roger Damton, The Kiss of Lamourette. Reflections in cultural history (New York 1990), pp. 107-135. La cultura libresca de otras áreas de América Latina, aunque más amplia, era similar a la del Valle Central. Manuel Reyes, Catálogo del Museo del libro antiguo (Guatemala 1971), pp. 129-165. Lawrence S. Thompson, Printing in Colonial Spanish America (Hamden 1962) y "The libraries of Colonial Spanish America": Bibliotheca Docet: Festgabe für Carl Wehmer (Amsterdam 1963), pp. 257-266. Thompson, sin embargo, se concentra en el analisis de las bibliotecas más conspicuas, al igual que Eleanor Adams y Frances Scholes, "Books in New Mexico, 1598-1680": New Mexico Historical Review, XVII (1942), pp. 226-270.
} 
El Valle Central se diferenciaba principalmente por la carestía de textos prohibidos y la escasez de literatura de entretenimiento: comedias, novelas y cuentos. Las obras de esta última especie, víctimas del desprecio de los ilustrados ${ }^{37}$, aparecían fugazmente $\mathrm{y}$, casi sin excepción, en las colecciones de los comerciantes; a lo sumo, se trataba de escritos de Racine, Quevedo, Calderón de la Barca y La Fontaine. La ausencia de una verdadera "biblioteca azul"38, con sus cancioneros, farsas, parodias y crónicas de amores y crímenes, era patente en una cultura libresca tan provinciana.

1:. : II. DEL COMERCIO A LA PRODUCCIÓN DE LIBROS

El universo librero empezó a cambiar velozmente tras 1821: siete años después, ya Rafael Francisco Osejo, ex-Rector de la Casa de Enseñanza de Santo Tomás, ofrecía vender al municipio de San José su biblioteca privada, la más amplia y erudita que existía en el país; compuesta de 80 títulos en 168 volúmenes, su dueño la valoraba en 578 pesos $^{39}$. La prensa, aparecida en 1833 , se colmó de debates de variado tipo, en cuyo transcurso la cita bibliográfica se aunaba con largos extractos de las obras en disputa ${ }^{40}$; y en mayo de tal año, en el

${ }^{37}$ Roger Damton, La gran matanza de gatos y otros episodios en la historia de la cultura francesa (México 1987), pp. 230-231. El estudio de la difusión de este tipo de literatura en Hispanoamérica fue el desvelo de Irving Leonard: entre sus diversos trabajos, Véase: "A shipment of 'Comedias' to the Indies": Hispanic Review, II (1934), pp. 39-50; "Notes on Lope de Vega's Works in the Spanish Indies": Hispanic Review, VI (1938), Pp. 277-293 y Books of the Brave (Berkeley 1991). El acervo de piezas literarias existente en el Valle Central de 1821 era, al parecer, más pobre que el de Honduras en el siglo XVII: según dos listas de 1673, esta última colonia importó, aparte de obras devotas, in variado conjunto de comedias. Héctor Leyva, Documentos coloniales de Honduras (Choluteca 1991), pp. 133-135.

3i Roger Mandrou, De la culture populaire awx 17e et 18e siècles: La Bibliotheque bleue de Troyes (París 1964). Geneviève Bolleme, Les almanachs populaires aux XVII et XVII' siècles. Essai d'histoire sociale (Paris 1969). El mejor estudio sobre este tipo de literatura para el caso español es el de Julio Caro Baroja, Ensayo sobre la literatura de cordel (Madrid 1969).

${ }^{39}$ González Flores, op. cit., pp. 103-106. El bachiller Rafael Francisco Osejo, oriundo de León de Nicaragua, fue contratado en 1814 por el ayuntamiento de San José para dirigir la Casa de Enseñanza de Santo Tomás, fundada ese mismo año. La venta de la biblioteca, sin embargo, no se efectuó aparentemente.

El periódico durante esos años era una forma de libro. Benedict Anderson, Imagined communities. Reflections on the origin and spread of nationalism (Londres 1983), pp. 3840. 
Noticioso Universal, se publicó el primer aviso indirecto de un texto. El propietario de un alambique europeo, lo vendía con su

“... tapa, y tomillos, 1 caja con la parte superior del mismo 56 cañones de cobre \&. El serpenton con la basija de madera, 1 cajonsito conteniendo dos termometros para graduar el calor del alambique. Original, y traduccion de las instrucciones para poner el alambique en obra, con su diceño correspondiente. El original del Ingenio de asucar, con sus diseños, completo á fin de evitar equivocaciones en su plantacion" ${ }^{4 !}$.

El uso apropiado de los últimos avances tecnológicos, traídos al país, exigía instructivos específicos, cuyo atractivo práctico se destacaba siempre en los avisos de venta de maquinaria. El estadounidense Herbert Parry, en diciembre de 1859, advertía en Nueva Era que vendía máquinas de coser de la prestigiosa firma "Grover and Baker", desde 75 pesos las más baratas; a los compradores "todas las instrucciones necesarias serán comunicadas, y un librito que contiene las mismas se dará gratis á cuantos quieran"42.

El período 1833-1859, que separa un anuncio de otro, fue propicio para el tráfico y el consumo de libros, editados en el país y traídos del exterior. Los avisos periodísticos que ofrecían obras en venta datan por lo bajo - de la década de 1840; en julio de 1845, se advertía en el Mentor Costarricense: "en esta imprenta [la del Estado] se venden cuadernos de Moral i aritmética, la Historia universal por Bossuet, un cuaderno de Logcia [sic], i un Diccionario español de un tomo en cinco pesos"43.

Los anuncios de libros, después de 1850 , aparecieron cada vez más en las páginas de los periódicos, frecuencia que estuvo vinculada con el despliegue del aparato educativo: en 1827, existían 50 escuelas con 2,429 alumnos $^{44}$ en el Valle Central, área que, según el Censo de 1843 , contaba con 61,714 habitantes, de los cuales un 18 por ciento - como máximo - tenía menos de nueve años ${ }^{45}$. ¿Cuántos eran en edad escolar? El total oscilaría entre 7,000 y 10,000 párvulos de ambos

${ }^{41}$ Noticioso Universal (San José), mayo 24, 1833, p. 168.

${ }^{42}$ Nueva Era (San José), diciembre 10, 1859, p. 4.

43 Mentor Costarricense (San José), julio 19, 1845. p. 375.

44 González Flores, op. cit., p. 180. Las escuelas de la época adolecían de graves deficiencias y limitaciones pedagógicas y materiales. Otras cifras posteriores de escuelas y escolares son un poco menores.

${ }_{45}$ Lowell Gudmundson, Costa Rica antes del café: sociedad y economía en vísperas del boom exportador (San José 1990), pp. 177-178 y 239-240. 
sexos, deducidos los menores de seis años y agregados los mayores de diez: a clases asistían dos o tres niños de cada decena ${ }^{46}$.

La falta de estadísticas óptimas impide visualizar con detalle el crecimiento educativo; pero ya en 1853, el viajero alemán Carl Scherzer calculó que existían 71 escuelas con unos 3,500 alumnos inscritos ${ }^{47}$. El alza en la población escolar fue un estímulo vital para los impresores criollos. "El Album", en mayo de 1858, avisaba que tenía

$\therefore . . .$. en venta el tratado elemental de aritmética compuesto por Don Lorenzo de Alemany, al precio de diez reales. Es el más completo en su clase que se encuentra entre nosotros, y ha sido designado como el más adaptable para la enseñanza primaria, por los profesores de este ramo, quienes aconsejaron se hiciera una edición con el "fin de facilitar el aprendizaje de los niños con buen escito [sic]. Se hace una rebaja á los que compren por docenas"48.

El incremento de la educación privada fue - evidentemente - más limitado, por lo que su impacto tuvo poco peso en la venta de obras; con todo, el tráfico librero se benefició de las clases de dibujo, música, idiomas y oficios. El profesor Tadeo Gómez fue cómplice de tal alza: tras alquilar una pieza en la vivienda de José María Flores, ubicada en San José, se promocionó en Nueva Era; en mayo de 1860 explicó que

“... deseoso de establecer formalmente la enseñanza de la Aritmética por Domingucz o D. Juan García, y la Teneduría de libros por Mars, ofrece dar clase en su habitación: para la primera, de las siete á las nueve de la mañana, y para la segunda de las tres á las cinco de la tarde; esceptuando el sábado de cada semana. El que haya de ocuparse en la Teneduría de libros, deberá proveerse de un ejemplar de la obra de dicho autor, en partida doble, y cuatro cuadernos reglados, conforme lo indica la misma obra"49.

La venta de otro tipo de impresos se derivó de exigencias prácticas de una época caracterizada por la expansión del café, eje de la capitalización del agro. El tiempo capitalista, con sus plazos para cumplir contratos y liquidar deudas, empezó a prevalecer en el quehacer diario. ¿Tiempo de relojes? Sí - en iglesias y casas, bolsillos y muñecas -y, a la vez, de calendarios, cuyo comercio se elevó tras 1850. El Album Semanal, en enero de 1858 , voceaba:

\footnotetext{
45 El cálculo tiende a subvalorar la proporción, ya que la población del Valle Central en 1843 era superior a la de 1827 , y no existían escuelas para niñas.

47. Moritz Wagner y Carl Scherzer, La República de Cosia Rica en la América Central. vol. 1 (San José 1974), p. 258.

48 Album Semanal, mayo 29, 1858, p. 4.

${ }^{49}$ Nueva Era, mayo 20, 1860, p. 4 .
} 
“ALMANAQUES PARA EL AÑO DE 1858 se espenden desde fines de Diciembre ... en cuaderno á tres reales y de sala ó pliego estendido á un real"50.

El tráfico de libros, aunque tenía por epicentro imprentas y librerías, no era exclusivo de tales locales. La importación de textos, durante la colonia una práctica esporádica y de exiguo atractivo para los comerciantes, suscitó un interés creciente en los años venideros. ¿Suficiente para promocionar el producto en la prensa? Sí en el caso de "J. Echeverría \& Cía": en agosto de 1859, avisó en la Crónica de Costa Rica que disponía ya de

"... la obra que acaba de publicar el Dr. Domingo Arosemena intitulada 'Sensaciones en Oriente', que contiene detalles curiosos, sobre los Santos Lugares. Suponemos que ella deberá ser leída con gusto por los buenos católicos. Consta de un solo volúmen que venderemos á dos pesos cuatro reales cada ejemplar, haciendo un descuento á los que compren diez ó más"'5!.

La estrategia publicitaria, en tomo al tráfico librero, fue tal que incluso se empezó a promocionar el texto previa su salida de la imprenta, con el evidente propósito de preparar el mercado y elevar las ventas. El periódico Pasatiempo, en agosto de 1857, acotaba:

"saldrá á la luz en la presente semana una obrita titulada CLARIN PATRIOTICO 6 colección de las canciones, y otras poesías, compuestas en Costa-rica en la guerra contra los filibusteros de Centro-América. - Las personas que quieran adquirirla podrán solicitarla en la casa de Don Jacinto García en esta capital"52.

¿Carácter comercial de la producción librera? El caso del Clarín patriótico lo patentiza. La antología, que aprovechaba las canciones y poesías compuestas durante la "Campaña Nacional", se editaba escasos cuatro meses después de concluida la guerra, que se extendió entre marzo de 1856 y mayo de $1857^{53}$. El poemario, con sus 13 piezas, era sin duda una obra de coyuntura; pero difícilmente constituía una excepción. El 10 de octubre de 1860, en el periódico Nueva Era, se publicó el siguiente aviso:

so Album Semanal, enero 22, 1858, p. 4.

51 Crónića de Costa Rica (San José), agosto 10, 1859, p. 5.

52 Pasatiempo (San José), agosto 20, 1857, p.4. El Clarín patriótico se editó por segunda vez 111 años más tarde. Véase: Revista de la ANDE, 26-29 (abril 1968), pp. 307-326.

${ }_{53}$ La "Campaña Nacional" es la designación oficial bajo la que se conoce la guerra emprendida por Costa Rica contra las fuerzas encabezadas por el estadounidense William Walker, traídas a Centroamérica por el Partido Liberal de Nicaragua. Rafael Obregón Lorla, Costa Rica y la guerra del 56. La Campaña del Tránsito (San José 1976). 
"se va á publicar un cuademo que contendrá una esposición histórica de la revolución: la coleccion de todos los boletines; y un plano de las fortificaciones. La suscrición [sic] vale un escudo que se pagará adelantado. En la capital podrán dirijirse á esta imprenta, y en las provincias a los respectivos gobernadores" 54 .

El conflicto, evocado por el aviso, es la fallida insurrección que encabezo, en septiembre de 1860 , Juan Rafael Mora, fusilado el último día de ese mes. El enfoque del opúsculo era, seguramente, poco objetivo: Nueva Era pertenecía a los adversarios del difunto. La edición de libelos, tras graves eventos civiles y militares, era usual ya en la década de 1830 , una vez se trajo la imprenta al país; pero se trataba casi siempre de textos de alcance limitado, cuyo fin era político más que lucrativo ${ }^{55}$. El Cuaderno, en cambio, era - pese a su decisivo trasfondo partidario -, un producto en esencia comercial: se cancelaria de antemano y circularía ampliamente.

$\therefore$ El consumo de libros, ¿creció lo suficiente para estimular el tráfico y la producción de obras? La promoción de "J. Echeverría \& Cía" y de "El Album" es de por sí elocuente. La persona que adquiriese diez ejemplares de las Sensaciones en Oriente de Arosemena, o una docena del Tratado elemental de Aritmética de Alemany, obtendría un atractivo descuento. La oferta era, sin duda, seductora para los buhoneros: al variado surtido de efectos (textiles, utensilios, enseres, adomos) que esparcían por campos y aldeas, agregaron diversos impresos, especialmente de carácter devoto.

El libro penetró en el pequeño comercio, uno de cuyos agentes fue José María Mora, carpintero y vecino de San José; al morir en octubre de 1834 , su fortuna ascendía a 1,016 pesos, de los cuales. 14 pesos eran el valor de 28 volúmenes, para un promedio de cuatro reales por texto. El acervo bibliográfico del difunto se componía de un ejemplar del Nuevo Testamento, 3 copias del Prontuario de leyes, 8 con el escalofriante título de Gritos del infierno y 16 Pantomimas $^{56}$.

${ }^{54}$ Nueva Era, octubre 10,1860, p. 4. El Presidente Juan Rafael Mora, en el poder desde 1849, fue derrocado en agosto de 1859; tras exiliarse en El Salvador, desembarcó en Puntarenas el 17 de septiembre de 1860 . La expedición, sin embargo, fracaso y 13 días después Mora cayó fusilado. Carlos Meléndez, Doctor José María Montealegre (San Jose 1968 ).

s5 Jorge Lines, Libros y folletos publicudos en Costa Rica durante los años 1830-1849 (San José 1944), p. 43.

6. ANCR, MISJ, exp. 1845 (1834). 
"Tinoco y Cía" - en contraste - disponía, en abril de 1859 , de 200 obras valoradas en 125 pesos ${ }^{57}$.

El interés de los importadores por traer libros en escala significativa se detecta ya tras 1830 ; pero casi siempre el cargamento venía por cuenta del Estado o de la Casa de Enseñanza de Santo Tomás. Esta última, ascendida a Universidad en mayo de 1843, adquirió - a mediados de la década de 1840 - más de 1,100 volúmenes de diverso tipo, en versiones españolas y francesas ${ }^{58}$. El alemán Edward Wallerstein, figura destacada en el comercio del café, estuvo involucrado en la transacción; en su casa, en febrero de 1845, “. . . está un cajón de dichos libros ... [por el cual la Universidad le debía] nueve pesos siete reales que ha pagado por el desembarque y conducción á esta ciudad del cajón referido" 59 .

El desvelo por aprovechar el periplo de un comerciante a Estados Unidos, Europa o Sudamérica, para ampliar la biblioteca tomasina, no privó únicamente en el caso de Wallerstein. La Universidad, en junio de 1850, contrató con el cafetalero Vicente Aguilar, de viaje para el Viejo Mundo, la compra de más de 600 volúmenes, cuyo valor se le cancelaría tras su vuelta, lo que ocurrió efectivamente en diciembre de 1851. El exportador de café, en compañía de Nazario Toledo - profesor de Filosofía - fue autorizado para adquirir

“... todos los libros de enseñanza primaria, secundaria y profesional, arreglándose en lo posible á las necesidades del establecimiento, y a las noticias y conocimientos que puedan adquirir para que los libros que adopten sean los precisos y mejores en cada ramo, según los progresos científicos del día ..."6ul

El comerciante contribuyó a elevar el consumo de obras y a diversificar su oferta. ¿Cuál fue el aporte de las imprentas? La edición de textos se aunaba con la de otros impresos: avisos de los municipios, folletos, volantes, comunicados del Poder Ejecutivo, colecciones de leyes y decretos y periódicos. El Estado y el claustro de Santo Tomás, dado el volumen de sus pedidos, destacaban entre la variada clientela de

57 Crónica de Costa Rica, abril 16, 1859, p. 2. "Tinoco y Cía" quebró en 1858 . El caso se comenta con detalle en: Bernardo Villalobos, Bancos emisores y bancos hipotecarios en Costa Rica, 1850-1910 (San José 1981), pp. 35-38 y 62-65.

${ }_{58}$ Mentor Costarricense, febrero 1, 1845, p. 288. Paulino González, La Universidad de Santo Tomás (San José 1988), p. 135.

59 ANCR, Educación (en adelante E), exp. 1102 (1845), f. 8.

${ }^{60}$ ANCR, E, exp. 3825 (1850), ff. 1-1 v. 
los talleres ${ }^{61}$; pero el aparato educativo, en su conjunto, era un estímulo vital. "El Album" editó el Tratado elementai de Aritmética por consejo de varios profesores, aval que garantizaba su venta.

La producción librera del país fue, sin embargo, bastante tradicional; aparte de textos escolares y oficiales, se concentró en obras de amplio consumo popular: cartillas, catecismos, catones, novenas, almanaques y otros. El josefino Miguel Carranza, según el Cuadro 3, se ciño a tal modelo: comerciante y caficultor, fue el que trajo la primera imprenta a Costa Rica, en 1830; al fallecer en septiembre de 1843, su caudal era de 44,668 pesos. El precio de la máquina ascendía a 1,200 pesos y el de los libros a 2,083 pesos, valor de 6,010 volúmenes, de los cuales sólo 39 constituían su biblioteca privada ${ }^{62}$.

El elevado valor de la imprenta del difunto evidencia lo difícil que era debutar en el universo editorial. La compra de tal artefacto caía fuera del alcance del grueso de los artesanos, cuyo caudal rara vez superaba los 1,000 pesos. El equipamiento de un taller exigía una suma cuantiosa, asequible únicamente para comerciantes de la talla de Carranza, cuyo desvelo no era especializarse en el oficio, sino diversificar sus actividades ${ }^{63}$. ¿Una alta inversión inicial? El arte de imprimir significaba eso y más: tecnología nueva, materias primas importadas y caras, una estricta división del trabajo y un disciplinado proceso productivo, cuya base era la exactitud y el esmero ${ }^{64}$.

El comercio exterior era evidentemente la vía por la cual se proveían de tinta, papel, utensilios y otros objetos los talleres de impresión, vanguardia de la capitalización artesanal. El importador - a veces trajo imprentas entre los artefactos que solía introducir al país, lo que hizo Rafael Moya, mayorista y terrateniente, vecino de Heredia; en mayo de 1833, avisó en las páginas del Noticioso Universal que, en el bergantín Emulons, venía “... 1 imprenta pequeña toda de fierro, 4 cajas de letras y otros avios para la misma ..."65

El artefacto - procedente de Europa - fue vendido, tres meses después, a Valentín Gallegos, un abogado nicaragüense que vivía en Alajuela desde 1829. El valor de la máquina ascendía a 700 pesos, suma

${ }^{61}$ Lines, op. cit., pp. 2-143.

62 ANCR, MISJ, exp. 148 (1843).

${ }^{63}$ Molina, Costa Rica (1800-1850), pp. 184-220 y 272-275.

64 Francisco María Núñez, La evolución del periodismo en Costa Rica (San José 1921), pp. 37-42.

65 Noticioso Universal, abril 24, 1833 , p. 168. 


\section{CUADRO 3}

Los títulos con más ejemplares en la imprenta de Miguel Carranza (1843)

\begin{tabular}{lccl}
\hline Título & Ejemplares & $\begin{array}{l}\text { Valor total } \\
\text { en pesos y } \\
\text { reales }\end{array}$ & $\begin{array}{l}\text { Valor por unidad } \\
\text { en pesos, } \\
\text { reales } \\
\text { y fracciones } \\
\text { de real }\end{array}$ \\
\hline Cartillas & 2,000 & 83.3 & $0.01 / 2$ \\
Trisagio & 1,048 & 16.3 & $0.01 / 8$ \\
Libros de pastores & 570 & $1,340.0$ & 2.3 \\
Madre e hijo & 425 & 106.2 & 0.2 \\
Catón & 305 & 107.5 & 0.3 \\
Despertador cristiano eucarístico & 293 & 88.4 & $0.21 / 2$ \\
Catecismo Ripalda & 252 & 63.0 & 0.2 \\
Ortografías & 243 & 25.2 & 0.1 \\
Vida de Cristo & 216 & 108.0 & 2.0 \\
Actos de fe & 162 & 3.3 & $0.01 / 4$ \\
Novena del Corazón de Jesús & 140 & 5.7 & $0.01 / 2$ \\
Novena de San Antonio & 105 & 8.6 & $0.03 / 4$ \\
Vía Crucis & 100 & 2.1 & $0.01 / 4$ \\
Novena de Nuestro Amo & 67 & 4.1 & $0.01 / 2$ \\
Novena de San Ramón & 45 & 2.6 & $0.01 / 2$ \\
\hline Total & 5,971 & $1,965.3$ & $0.23 / 4$ \\
\hline
\end{tabular}

Fuente: ANCR, Mortuales Independientes, San José, exp. 148 (1843), ff. 8-41.

que el comprador cancelaría a un año plazo. La deuda fue garantizada por el josefino Eusebio Rodríguez y el español Manuel Cacheda; pero el jurisconsulto defraudó la confianza de uno y otro: varios años más tarde, se trasladó a León - ¿con la imprenta? - sin cumplir su compromiso. Los fiadores, en tal apuro, autorizaron a Pedro Pablo Alvarado, en junio de 1837, para cobrarle lo adeudado ${ }^{66}$.

El espíritu empresarial que - desde temprano - prevaleció en la estructura editorial de San José, se dibuja en las vicisitudes del aparato traído por Moya y comprado por Gallegos. El éxito económico de los impresos, tras 1830, se derivó de varias circunstancias: despliegue educativo público y privado, crecimiento demográfico, urbanización

${ }^{66}$ ANCR, PCSJ, exp. 499 (1833), f. 59 v. y exp. 514 (1837), ff. 26 v. -27 v, 
del casco josefino, expansión del Estado y venida de comerciantes y artesanos europeos, y de profesionales de Guatemala, El Salvador y Nicaragua ${ }^{67}$. La diferenciación social sirvió de base para la especialización de - cada vez más amplias - audiencias de lectores: de los escolares, usuarios del viejo Catecismo de Jerónimo Ripalda, a los aficionados a Jas obras de Byron, Chateaubriand y Walter Scott.

El atractivo comercial del libro se elevó poco a poco, a raíz de un significativo aumento en el consumo: en 1850, era superior el número de lectores y se leía más; a la vez, se disponía del efectivo suficiente para comprar un variado espectro de cosas, en cuenta textos. El café, de excelente cotización en el exterior, deparó utilidades crecientes, de las que no se excluyó a los pobres. El sueldo por mes de un peón subio de 7 a 15 pesos entre 1844 y $1856^{68}$. El ingreso familiar se ampliaba con el aporte de la esposa y de los hijos, aparte de que casi siempre se disponía de un pedazo de tierra propio.

El precio promedio de los libros de Carranza (casi tres reales) suponía como máximo el 5.4 por ciento del salario mensual de un jornalero en 1844 , y un 2.5 por ciento en 1856. ¿Una proporción descendente en una época en que se elevaba el coste de la vida? El valor de los víveres y de la tierra, entre 1830 y 1850 , se multiplicó por más de cinco $^{69}$; con todo, en el siglo posterior a 1750 , la cotización de los textos no varió decisivamente. ¿Por qué? El texto extranjero, traído por lo común de España y Francia, se abarató en virtud del contacto directo entre Costa Rica y las plazas europeas, y de la baja en los costos editoriales en Europa, que se derivó del uso de tecnología más avanzada ${ }^{70}$.

La cotización de los libros editados en el país dependía de otro factor, El dueño del taller, aunque capaz de invertir en equipo nuevo ${ }^{71}$, optaba por ir a lo seguro: contratar con el Estado las impresiones

${ }^{67}$ Molina, Cosia Rica (1800-1850), pp. 183-336.

${ }^{68}$ Ciro Cardoso, "La formación de la hacienda cafetalera en Costa Rica (siglo XIX)": Avances de Investigación. Proyecto de historia social y económica de Costa Rica. $1821-1945,4$ (1976), p. 21.

"69 Víctor Hugo Acuña e Iván Molina, Historia económica y social de Costa Rica (1750-1950) (San José 1991), p. 87.

${ }_{70}$ Dahl, op. cit., pp. 230-231.

$"$ Francisco María Núñez, "150 años de periodismo": El desarrollo nacional en 150 años de vida independiente (San José 1971), pp. 257-258. Entre los avances tecnológicos, figuraba el uso de boyas de cuero para suministrar la tinta, después sustituidas por los rodillos de cola. 
oficiales y publicar obras baratas de fácil venta ${ }^{72}$. El enfasis en la edición de textos cortos, de carácter devoto y escolar, devela que la oferta de las imprentas se circunscribía a lo que exigía el mercado. La especialización en productos dignos del gusto popular permitiría eventualmente - exportarlos a los demás países del istmo, donde el patrón de consumo era bastante parecido.

El difunto Carranza era un veterano en las lides editoriales: con sus cientos de "obritas" baratas y ligeras, conocía lo que le convenía a su taller; y lo supo desde el inicio: ya en 1830, publicó en su imprenta "La Paz" un escrito de Osejo, titulado Brebes lecciones de arismetica, para "... el uso de los alumnos de la Casa de Santo Tomás ..." $" 73$ El taller editó en los siguientes dos años, varios textos oficiales y particulares $\mathrm{y}$, en 1832, publicó Reflexiones sobre la necesidad de una reforma política en Centroamérica, de José Caleja y Unane, "... reimpreso [de la primera versión publicada en New Amsterdam] a despensas [sic] de algunos Vecinos, en San José ..."74

La práctica de la piratería editorial se extendió con presteza: en 1833, "La Paz" editó Lecciones de geografía, de R. Ackerman, con un apéndice sobre Costa Rica escrito por Osejo; y La infancia de Jesucristo, un poema dramático en diez coloquios, del cura español Gaspar Fernández y Avila ${ }^{75}$. Las otras imprentas emularon sin demora a la de Carranza, en la que ya se imprimía el periódico Noticioso Universal. El taller "La Libertad", en 1834, publicó Medicina moderna cacera o tratado popular, del británico Tomás Juan Graham; con sus 750 páginas, fue - quizá - el producto impreso más volumi$\operatorname{noso}^{76}$.

El esfuerzo empresarial, cuyo afán era editar textos vendibles, contribuyó poco a variar las preferencias literarias de los lectores. El

${ }^{72}$ Esta estrategia empresarial prevalecía en otros países de América Latina y en España. Francesc Burgos y Manuel Peña, "Imprenta y negocio del libro en la Barcelona del siglo XVIII. La casa Piferrer": Manuscrits. Revista d' historia moderna, 6 (dic. 1987), pp. 181-216; Medina, op. cit:; Thompson, Printing in Colonial Spanish America; Rafael Heliodoro Valle, Hisroria de la cultura hondureña (Tegucigalpa 1981), pp. 14-15. El caso de Costa Rica empieza a ser estudiado en detalle por Patricia Vega en La imprenta: instrumento de progreso. Costa Rica (1821-1850) (San José 1992), pp. 1-30. Carranza imprimió, entre 1831 y 1832, más de 15,000 ejemplares de leyes, decretos y otras disposiciones oficiales por un valor de $1,3,30$ pesos.

${ }^{73}$ Lines, op. cit., p. 2.

${ }^{74}$ Ibidem, p. 16.

75 Ibidem, pp. 22-23 y 28-29.

${ }^{76}$ Ibidem, pp. 34-35. 
espacio para proyectos editoriales osados era exiguo, dada la fuerte competencia entre las imprentas: de 1830 a 1850 , se editó una quincena de periódicos y, en 1848, ya existían - por lo bajo - seis talleres ${ }^{77}$. La producción librera, dado el tipo de mercado que debía satisfacer, discurrió en esencia por cauces tradicionales; su aporte, más cuantitativo que cualitativo, fue ampliar el acceso - el del vulgo sobre todo - a un vasto conjunto de obras livianas, del Catón al Almanaque.

El alza en la oferta de impresos carecía de precedentes: en abril de 1829, el español y comerciante, Manuel Díez de Bedoya, vecino de Cartago, poseía 155 Cuadernillos, valorados en 9.5 pesos $^{78}$; en marzo de 1846, el cura y traficante de Heredia, José Emigdio Umaña, tenía 60 ejemplares de Discurso en medicina, estimados en 15 pesos ${ }^{79}$; y en septiembre de 1847, José Antonio Oreamuno, caficultor cartaginés, disponía de 142 Cuadernillos de rezo, tasados en 8.6 pesos $^{80}$. Las cifras opacan, sin duda, los 24 Catecismos y las 25 Cartillas de que era dueño Pedro Antonio Solares en 1824.

El acervo de los comerciantes, sin embargo, era ínfimo a la par de las existencias de los impresores, con sus cientos y a veces miles de volúmenes; diferencia cuyo significado se vislumbra al contrastar la cuantía de textos con los datos demográficos. El finado Miguel Carranza, en septiembre de 1843 , poseía 425 ejemplares de Madre e hijo, 570 Libros de pastores, 1,048 Trisagios y 2,000 Cartillas. El censo efectuado ese año contabilizó 56,216 almas y 12,018 familias en las poblaciones principales del Valle Central ${ }^{81}$; en promedio, por cada 28 personas y por cada 6 hogares, se disponía de una Cartilla con el sello de "La Paz".

La oferta de libros, tradicional en el caso de la producción editorial, varió y se diversificó en alas del comercio. El importador, aunque traficaba ampliamente con vulgarizadores, traía - por cuenta de otro o por la suya propia - textos de distintos tópicos, en cantidades limitadas: títulos selectos, en varios tomos, extensos y caros. ¿Y los compradores?

${ }^{7}$ Ibidem, pp. xx-xxi. Adolfo Blen, El periodismo en Costa Rica (San José 1983), pp. 13-65.

78 ANCR, MIC, exp. 1127 (1832). Su fortuna ascendía a 10,407 pesos.

79 ANCR, MIH, exp. 3262 (1846). Su fortuna ascendía a 15,909 pesos.

an ANCR, MIC, exp. 2389 (1847). Su fortuna ascendía a 18,090 pesos.

8. Gudmundson, Costa Rica antes del café, p. 123. Las cifras proceden de los centros y barrios de San José, Alajuela, Cartago y Heredia. 
El espectro era diverso: estudiantes y docentes universitarios, profesionales, funcionarios, burgueses y ciertos artesanos; ávidos de saber y esparcimiento, disponían de dos opciones principales: la biblioteca tomasina y la librería de la imprenta "El Album".

\section{DE VISITA EN UNA BIBLIOTECA, DE COMPRAS EN UNA LIBRERÍA}

El aficionado a la lectura, ¿gustaría de las obras de la biblioteca de Santo Tomás, abierta al público a partir de febrero de 1859? El Cuadro 4 , cuya fuente es un inventario efectuado en marzo de tal año, traza un perfil básico del material existente. El carácter especializado y secular de la colección destaca con presteza; se trataba - en su mayoría de trabajos de Filosofía, de Ciencias exactas y naturales y de Literatura y diversas disciplinas sociales: Geografía, Historia, Derecho, Economía y Política. El porcentaje de textos religiosos era - en contraste bastante bajo: en tal categoría, la obra de más peso era Selectas sagradas, una antología compuesta por 65 tomos en latín y en castellano $^{82}$.

El área de Filosofía, aparte de las obras de Teodoro de Almeida y de Jaime Balmes, contaba con la Retórica de Blair y los manuales de Baeza, López de Uribe, Urcullo y Vallejo; sin embargo la influencia gala era decisiva: Condillac, Voltaire, Rousseau y Destutt de Tracy con sus Elementos de ideologí. El predominio francés se evidenciaba a la vez en otros campos: en Política, con La democracia en América de Tocqueville y El espíritu de la leyes de Montesquieu; en Historia con la Historia universal de Segur, la Historia de Francia de Sismondi - uno de los teóricos iniciales del Socialismo - y la Historia de la Revolución de Francia de Thiers; y en Geografía con Letronne.

El Derecho era un campo en el que la influencia española era relevante, pero no única: además de Los códigos españoles en 12 tomos y de los textos de Febrero, Salas y Ortiz, se disponía del Derecho de gentes del alemán Samuel Pufendorf; de la Teoría de las penas y recompensas, de la Legislación civil y penal y de otros libros de Jeremy Bentham; del Derecho canonico de Domingo Cavalario y de un par de obras del italiano Burlamaqui, en cuenta su Derecho natural, el cual

${ }^{82}$ De los 2,981 volúmenes de la biblioteca universitaria, 1,155 estaban en francés. La biblioteca fue abierta al público desde 1859 y no a partir de 1865 , como indica González, op. cit., p. 135. 


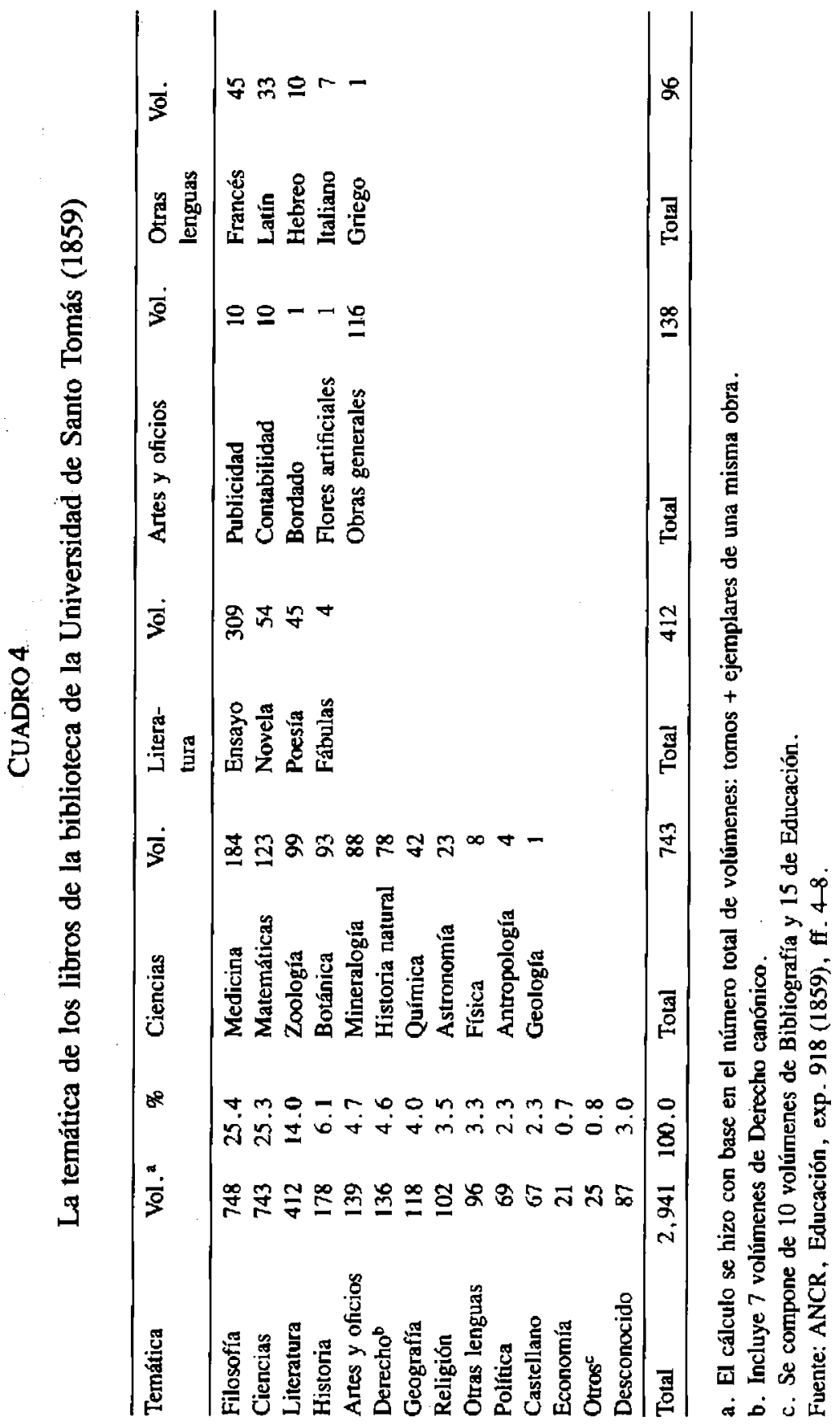


fue publicado en Génova en 1754 y prohibido por la Inquisición en diciembre de $1756^{83}$.

El aporte británico, distinguido por los trabajos de Blair y Bentham (del cual se tenía en un tomo la Defensa de la usura), abarcaba a la vez el Tratado de la Síflis de Hunter, la Astronomía de Ferguson, la célebre Historia de América de William Robertson, y el clásico la Riqueza de las naciones, en una edición francesa y otra española. El texto de Adam Smith brillaba, a todas luces, entre el Catecismo de Economía política de Ackerman y los escritos del teórico francés Charles Ganilh, de cuya obra la Universidad poseía dos títulos: Diccionario de Economía política y Teoría de Economía política.

El campo de las ciencias era estadísticamente significativo: concentraba casi el 25 por ciento del total de volúmenes, pero ofrecía un contraste evidente con las obras filosóficas, políticas e históricas. El escritor de primera línea - Rousseau, Voltaire, Condillac, Robertson, Smith - prevalecía en el área de "letras". Los textos científicos, sin embargo, eran en su mayoría "catecismos" y "cuadernos", simples vulgarizadores de conocimiento, con pocas excepciones: la Química orgánica de Liebig, la Historia natural de Buffon, el Viaje a las regiones equinocciales del Nuevo Continente de Humboldt, el Diccionario de Física de Brisson y la Aritmética de Lacroix.

La colección literaria, con un fuerte peso de los clásicos griegos y latinos, tampoco era muy extensa: en poesía, textos de Virgilio, Ovidio, Lamartine y Béranger; en fábulas, las de Iriarte; y en novela, las de Chateaubriand. La mayoría de los textos eran ensayos, entre los cuales figuraba - en catorce tomos - el Curso de literatura de Laharpe. La obra específica, sin embargo, era excepcional: prevalecía la antología, cuyo ejemplo más distinguido era la Biblioteca latina y francesa, en 177 volúmenes, publicada por el francés Charles Joseph Panckoucke, uno de los editores de la Enciclopedia ${ }^{84}$.

La enseñanza de otros idiomas, falta de un amplio soporte bibliográfico, dependia en esencia de gramáticas y diccionarios, en especial franceses y latinos; curiosamente, el inventario no enlista obras para el aprendizaje del inglés, una asignatura que se empezo a impartir desde $1846^{85}$. El énfasis que se otorgó a otro tipo de textos

\footnotetext{
${ }^{83}$ Ramos Soriano, op. cit., p. 45.

${ }^{84}$ Darnton, The business of Enlightenment, pp. 17-25.

${ }^{85}$ González, op. cit., pp. 94-95.
} 
fue - en contraste - superior; se disponía de más de un centenar de volúmenes prácticos: enciclopedias de artes y oficios y unos pocos títulos especializados, como un manual de Bordado y una decena de ejemplares de la Teneduría de libros de Degrange, una materia que se enseñó efímeramente, durante el trienio 1872-187486.

¿Libros para todos los gustos? La biblioteca universitaria, aunque amplia, era selectiva. El grueso de la colección se componía de obras filosóficas, jurídicas, históricas, políticas, económicas y científicas, cuya consulta atraía - eventualmente - a una audiencia de lectores más intelectual. El texto devoto era casi una excepción y se disponía de poco material para la enseñanza de idiomas y oficios; a la vez, entre las escasas piezas literarias, era evidente la falta de los escritores de éxito de la época: Dumas, Scott, Byron, Sue, Dickens. La ausencia obedecía - quizá - al prejuicio ilustrado que asociaba la literatura contemporánea con el esparcimiento, un atributo impropio de un claustro serio y grave; en junio de 1845, en el Mentor Costarricense, se decía: “... el que quiera divertirse puede leer á Walter Scott, Paul de Kock, Fígaro, \&"87.

La "diversión", trece años después, tenía un epicentro: la librería de la imprenta "El Album", abierta en septiembre de 1856 por Carranza y Cauty ${ }^{88}$. El Cuadro 5, que precisa la temática de las obras en venta, devela significativas diferencias con la biblioteca de Santo Tomás. El peso de los textos literarios, en especial novelas, era decisivo. El catálogo ofrecía, entre otras piezas, el clásico Las Mil y una noches, El castillo peligroso y El Talismán de Scott, El corsario de Byron, El vizconde de Bragelonne de Dumas, El último Abencerrage de Chateaubriand y El vampiro de Polidori ${ }^{89}$.

La categoría de obras devotas, con casi un 29 por ciento del total de volúmenes, era estadísticamente fuerte; pero exhibía pocas variaciones con los impresos píos del ocaso colonial. Los títulos son elocuentes: Coloquios con Jesucristo, Alma al pie del Calvario, Finezas de María, Manual de desagraviar a Cristo. "El Album", sin embargo, disponía de otros textos más conspicuos: Las delicias de la religión de Lamourette, editada en Francia en 1788 y traducida al español en 1796; y El

\footnotetext{
${ }^{\text {o6 }}$ Ibidem, p. 94. Las clases de Teneduría de libros, tras 1874, pasaron al Instituto Nacional.

Mentor Costarricense, junio 28, 1845, p. 363.

${ }^{88}$ Blen, op, cit., p. 101.

${ }^{89}$ El vampiro era una obra atribuida en esta época a Lord Byron; sin embargo, la misma fue escrita por su secretario y víctima, John William Polidori (1795-1821).
} 


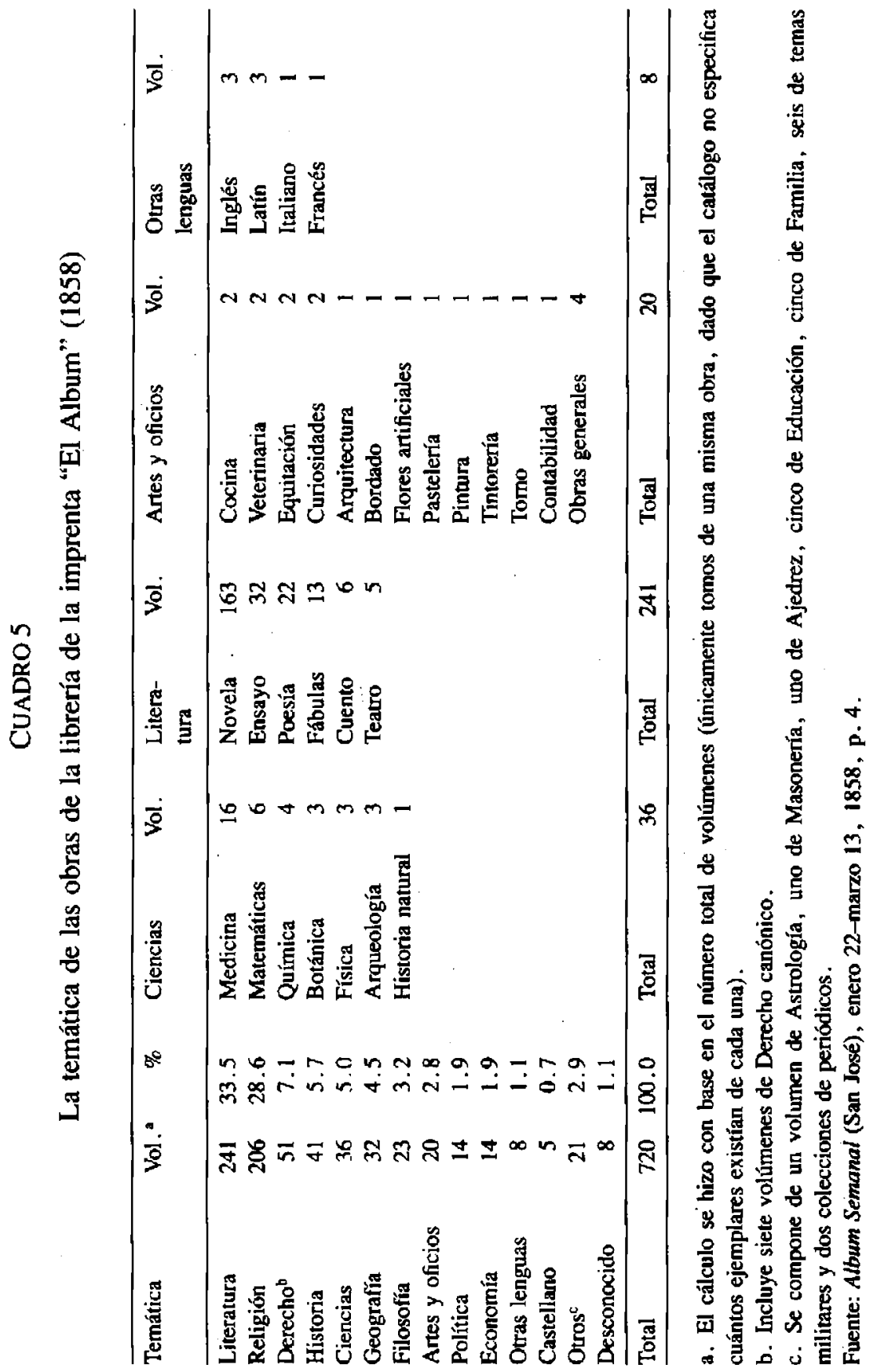


Evangelio en triunfo, escrita por Pablo de Olavide en 1796, tras el proceso que le siguió la Inquisición entre 1776 y $1778^{90}$.

El conjunto de libros científicos y filosóficos se parecía a la colección de la biblioteca tomasina; incluso, la librería de "El Album" disponía de títulos ausentes en las estanterías universitarias. Las obras más interesantes eran Mis prisiones, memorias de Silvio Pellico, Economía politica de J. B. Say, Derechos del hombre de Thomas Paine, Cartas persianas de Montesquieu, Lecciones de Química de Girandin y Física de Despretz. El atractivo de otros textos, cuyo autor no se especificó, tampoco era inferior: Revolución de 1830, Análisis del socialismo e Historia de la sociedad, quizá el ensayo de Ferguson ${ }^{91}$.

El catálogo, que ofrecía un Compendio de Arqueología en tres tomos, disponía de varios volúmenes para la enseñanza de oficios, y de $E l$ verdadero francmasón, un Oráculo novisimo y el Arte de ajedrez de Philidor (1647-1730). El estímulo para vender ese texto, en el San José de 1858, se derivó del éxito creciente de los juegos de mesa, una diversión difundida por los extranjeros. El comerciante J. Guzmán fue un promotor de tal entretenimiento; especializado en perfumería y ótros artículos de tocador, tenía para la venta, en abril de 1859, varios “... juegos de ajedrez y dominó"92.

La comparación de la biblioteca de Santo Tomás con la librería de "El Album" devela varias tendencias básicas: en un contexto de veloz secularización del universo librero, el texto devoto se identificaba con el gusto popular, artesano y campesino; en cambio, las obras profanas empezaron a colmar las estanterías de los sectores urbanos acaudalados. El grueso de tales lectores, sin embargo, optaba por "divertirse" con diversas piezas literarias (cuentos, novelas), más que por "ilustrarse" con los serios escritos de filósofos y economistas. El aficionado a los libros de Smith y de Say pertenecia a un círculo más intelectual, de profesionales vinculados con el claustro universitario.

\footnotetext{
90 Marcelin Defoumeaux, Pablo de Olavide ou l'afrancesado: 1725-1803 (París 1959). John Adams, embajador de Estados Unidos en París, aseveraba que la obra de Olavide era una parafrasis del texto de Lamourette. Márquez, op. cit., pp. 94-95.

${ }^{11}$ Essay on the history of civil society (Londres 1767). La identificación de las obras ee dificulta porque en el catálogo los títulos se publicaron abreviados.

$\therefore{ }^{2}$ Crónica de Costa Rica, abril 20,1859, p. 4. El anuncio de Guzmán sugiere que dominó y ajedrez eran apropiados para damas y caballeros; en contraste, los juegos de naipes y de dados, que prevalecían a fines de la colonia, eran primordialmente masculinos. Lowell Gudmundson, "Los juegos prohibidos y el régimen colonial en Costa Rica": Revista de Historia, 5 (diciembre 1977), pp. 171-185.
} 
La libreria, ¿era un eficaz soporte para la docencia tomasina? El catálogo de "El Album", con su énfasis en lo devocional y lo literario, difícilmente satisfacia las exigencias de los profesores y estudiantes de Santo Tomás; en su conjunto, las obras especializadas, en los campos científicos y sociales, ascendían a un modesto 29.3 por ciento del total de volúmenes dispuestos para la venta. La oferta de textos se adaptaba a los gustos prevalecientes de los lectores, en su mayoría sin lazos con la Universidad; desfase que obligó a la última a surtirse del exterior para ampliar los títulos de su biblioteca ${ }^{93}$.

El acceso desigual a los libros profanos - en especial a los de ficción - se trasluce en los inventarios sucesorios efectuados, en el Valle Central, entre 1825 y 1850 : de 1,177 casos, se avaluaron libros en 223, de los cuales por lo menos en 21 aparecían diversas piezas literarias, cuya distribución ofrece el Cuadro 6 . El caudal promedio de sus dueños era de 7,662 pesos; el valor promedio de cada título ascendía a 2 pesos con 6 reales y el de cada volumen a 1 peso con 4 reales. El precio de tales textos (entre un tercio y un cuarto del salario mensual de un peón en 1844) era muy superior al del vulgarizador devoto: el Catecismo de Ripalda, impreso por Carranza, valía 0.2 reales en 1843.

\section{CUADRO 6}

Novelas, cuentos y dramas en los inventarios sucesorios de los años 1825-1850

\begin{tabular}{lcllll}
\hline $\begin{array}{l}\text { Nivel de } \\
\text { fortuna en } \\
\text { pesos }\end{array}$ & $\begin{array}{l}\text { Inventarios } \\
\text { con piezas } \\
\text { literarias }\end{array}$ & $\begin{array}{l}\text { Número de } \\
\text { tomos }\end{array}$ & $\begin{array}{l}\text { Número de } \\
\text { títulos }\end{array}$ & $\begin{array}{l}\text { Valor por } \\
\text { unidad en } \\
\text { pesos }\end{array}$ & $\begin{array}{l}\text { Número de } \\
\text { títulos }\end{array}$ \\
\hline$-1,000$ & 2 & 1 & 32 & -1 & 21 \\
$1,000-1,999$ & 4 & 2 & 10 & $1-2$ & 17 \\
$2,000-4,999$ & 4 & 3 & 5 & $3-4$ & 8 \\
$5,000-9,999$ & 5 & 4 & 5 & $5-8$ & 4 \\
$10,000-19,999$ & 4 & 5 & 1 & $9-12$ & 4 \\
20,000 y más & 2 & 6 & 2 & $13-14$ & 1 \\
\hline Total & 21 & Total & 55 & Total & 55 \\
\hline
\end{tabular}

Fuente: ANCR, Mortuales Independientes, San José, Alajuela, Heredia y Cartago (1825-1850).

${ }^{93}$ Para un desfase similar, véase: Carlos Alvarez, "Librerías y bibliotecas en la Sevilla del siglo XVIII": La documentación notarial y la historia, vol. 2, pp. 168-185. 
La difusión de los impresos profanos, según los inventarios sucesorios, fue bastante limitada en las décadas de 1820 y 1830 , periodo en el que se efectuaron - únicamente -6 de los 21 procesos en que se avaluaron piezas literarias. Los otros 15 casos eran posteriores a 1840 , que fue el año en que despegó la exportación de café ${ }^{94}$. El todavía exiguo comercio librero era incapaz de esparcir, en amplia escala y velozmente, obras de este tipo, cuyo elevado valor tampoco facilitaba su venta: un Quijote de Cervantes valía diez pesos en 1825 y una Historia de América de Robertson se valoró en cinco pesos en $1839^{95}$.

La penetración de las obras profanas, sin embargo, era ya evidente a fines de la década de 1840 entre los vecinos principales, categoría en la que figuraba don Manuel Esquivel, caficultor de San José: muerto en mayo de 1847 , su fortuna ascendía a 13,364 pesos. La biblioteca del finado, compuesta por 37 títulos en 95 volúmenes, se valoró en 106 pesos; entre otras piezas, poseía Las amistades peligrosas de Laclos, El judio errante y Misterios de París de Sue, Don Juan, Lara y Manfredo y Cain de Byron, Don Carlos de Schiller, El vampiro de Polidori y Cornelia Bororquia de Fermín Araujo ${ }^{96}$.

\section{LOS LIBROS Y EL CAMBIO CULTURAL}

Wilhelm Marr, viajero alemán que visitó Costa Rica en 1852, describió vívidamente las principales casas de San José:

"se ven ventanas de vidriera, habitaciones entarimadas y paredes empapeladas de diversos colores ... Sin ofrecer un confort en el sentido que nosotros le damos a esta palabra, la tendencia a imitar lo europeo se hace sentir más sin embargo. Ya es un magnífico piano que forma extraño contraste con las dos docenas de modestas sillas de rejilla arrimadas a la pared, faltando el resto de los muebles; ya son dos elegantes sofás colocados muy cerca el uno del otro, que hacen más notorio lo que falta ... se

${ }^{94}$ La exportación de café de Costa Rica se elevó de 8,341 a 96,544 quintales entre 1840 y 1848. Clotilde Obregón, "Inicio del comercio británico en Costa Rica": Revista de Ciencias Sociales, 24 (octubre 1982), p. 67.

. 95 El Quijote pertenecía a Antonia Alvarado, viuda del comerciante cartaginés José Antonio Alvarado, fallecida en 1825, con una fortuna de 6.652 pesos; y la Historia de América a un vecino de Heredia, Rafael Moya (el que importó la imprenta que compró Valentín Gallegos), dueño de un caudal de 28,301 pesos en 1839. ANCR, MIC, exp. 114 (1825) y MIH, exp. 2907 (1839).

î: 96 . Esta última novela, que atacaba a la Inquisición, era célebre en la época. Márquez, op. cit., pp. 180-181. 
ven preciosos espejos colgando de una pared blanca, en medio de bancos de madera toscamente tallados y de sillas ordinarias de mimbre ..."97

El contraste entre lo antiguo y lo nuevo, descrito por el visitante, evidencia una temprana diversificación en los patrones de consumo, especialmente en los urbanos. El cambio se vislumbraba en la coexistencia de viejas bancas criollas con sofás alemanes, de pianos con vihuelas, de lámparas y relojes con imágenes sagradas, del aguardiente del país con champaña, oporto y jerez, de almendras, pasas y nueces con las frutas ordinarias, del tasajo y el queso Turrialba con el jamón de Westfalia y los quesos de Holanda, de las zarazas y el dril con las sedas y los casimires, del calzado francés de charol con las botas de cuero de becerro, de los sombreros de copa con los de palma ${ }^{98}$.

La arquitectura doméstica tampoco era ya la de antaño: varió con la construcción de casas de dos plantas, de piso entablillado, paredes empapeladas y ventanas de cristal. El casco josefino, líder de tal despliegue urbano, dispuso después de 1850 de un conjunto de edificios sin precedente: entre otros, el Palacio Nacional, el Teatro Mora, la Universidad de Santo Tomás, la Fábrica Nacional de Licores y el Hospital San Juan de Dios. El empedrado de las calles, iniciado en 1837 , se aunó con el alumbrado de canfín en 1851 , y con la instalación de una cañería de hierro en $1867^{99}$.

El avance en las obras de infraestructura sirvió de base para el crecimiento de diversas actividades y servicios urbanos: San José especialmente fue espacio optimo para la apertura de clubes, fondas, hoteles, restaurantes y posadas; la venta - en botellas - de agua potable de la Fábrica Nacional de Licores; el alquiler de caballos, yeguas y mulas; el funcionamiento de caballerizas y de una línea de diligencias entre la capital y Cartago; la instalación de tiendas, almacenes, boticas, talleres, bufetes y consultorios; y la enseñanza privada de variadas destrezas, de la teneduría de libros al dibujo topográfico ${ }^{100}$.

\footnotetext{
${ }^{97}$ Ricardo Fernández Guardia (ed.), Costa Rica en el siglo XIX. Antología de viajeros (San José 1983), p. 164.

${ }^{98}$ Patricia Vega, "De la banca al sofá. La diversificación de los patrones dè consumo en San José (1857-1861)": Iván Molina y Steven Palmer, Héroes al gusto y libros de moda. Sociedad y cambio cultural en Costa Rica (1750-1900) (San José 1992), cap. IV.

99 José Luis Vega Carballo, Hacia una interpretación del desarrollo costarricense. Ensayo sociológico (San José 1983), pp. 197-202.

100 Patricia Fumero, "La ciudad en la aldea. Actividades y diversiones urbanas en San José a mediados del siglo XIX": Molina y Palmer, op. cit., cap. III.
} 
El casco josefino, que disponía de 80 cuadras centrales delineadas ya en $1850^{101}$, se convirtió sin tardanza en el eje del entretenimiento (billares, galleras) y de la vida nocturna. El Teatro Mora, cuyas funciones empezaban a partir de las 8 de la noche, se inauguró con una comedia de Bretón de los Herreros, ejecutada por una "Sociedad dramática de aficionados"; un año después, en diciembre de 1851, debutó la compañía del español Mateo Fournier, primer elenco profesional que vino al país. El grupo interpretó, entre otras piezas, Otelo de Shakespeare y Lucrecia Borgia y Pablo el Marino de Dumas $^{102}$.

La capitalización del agro, encabezada por el cultivo del café, supuso decisivas variaciones económicas y sociales: privatización de la tierra, expansión del crédito, auge del comercio exterior y alza en la compra y venta de fuerza de trabajo. La construcción de una economía nacional y del Estado fue el trasfondo de un amplio cambio cultural, que empezó a trastocar los antiguos patrones de vivienda, consumo, diversión y vida cotidiana. ¿Y los libros? La oferta de obras, en tal contexto, se transformó velozmente: transitó de la escasez a la abundancia y de lo devoto a lo profano.

El proceso de cambio comportó a su vez una creciente diferenciación cultural, notoria en el caso de los libros: artesanos y campesinos seguían fieles a un cuerpo de impresos tradicionales; pero en las casas de los vecinos acaudalados, se disponía de las obras de Robertson y Smith, Byron y Sue. El contraste, cierto especialmente para San José, era social y geográfico: tras 1830, se profundizó la división ciudad-campo. El espacio urbano, asiento del comercio y la artesanía, empezó a construir una cultura propia; con el brillo de sus diversiones, servicios y actividades, pronto opacó al entomo agrario circundante.

¿Identidades urbanas? Sí, y de clase: en los céntros de San José, Alajuela, Cartago y Heredia, una burguesía agrícola y comercial, que prosperó con el café, descubría que la distinción y el buen gusto se vinculaban con lo de fuera: degustar un queso de Holanda, beber una copa de jerez, descansar en un sofá alemán, usar sal inglesa, tocar el piano, oír el cadencioso tic-tac de un reloj francés, leer a Walter Scott, vestir un traje de seda, defecar en un excusado. La europeización, sin

101 Vega Carballo, op. cit., p. 197.

102 Blen, op. cit., pp. 67-68. 
embargo, significó aún más: adoptar el ideario de la llustración, la Economía política y el Liberalismo y practicar la Masonería ${ }^{103}$.

El universo de campesinos y artesanos, prosaico, de duro trabajo diario y de profunda raíz española y católica, era lo opuesto del mundo burgués que, con sus gustos y modas, se definía respetable y refinado. La burguesía se distinguió del grueso de los productores, libres y usualmente propietarios, a partir de la cultura: viviendas, educación, enseres, comportamientos, libros, ideologías, vestuario. La experiencia en países vecinos fue distinta, la diferenciación social, aparte de su expresión cultural, se basó en criterios estamentales y étnicos, afirmados por medio de la coerción; tal fue el caso de Guatemala ${ }^{104}$.

La inmigración de comerciantes, artesanos y profesionales, oriundos de España, Suiza, Italia, Inglaterra y Alemania, estimuló una temprana europeización de la burguesía criolla. El aporte europeo, vital para actualizar las técnicas empresariales y la tecnología, se extendió con fuerza en la esfera de la cultura. El impacto de los inmigrantes, en sí un grupo poco numeroso, fue de tipo cualitativo, más que cuantitativo; desequilibrio favorecido porque el medio que los acogió era en extremo pequeño y provinciano. El éxito económico que alcanzaron se patentiza en las estadísticas: a fines del siglo XIX, cerca del 20 por ciento de los beneficiadores y exportadores de café (la clase más poderosa de Costa Rica) era de origen extranjero ${ }^{105}$.

La influencia cultural del inmigrante cristalizó en diversos campos: impartió clases privadas y públicas, actuó en el Teatro Mora, administró imprentas, ejerció variadas ocupaciones (oficios artesanales, medicina, fotografía, periodismo, abogacía) y, en la diversificación del consumo, su liderazgo fue decisivo; adalid de lo europeo, difundió otras conductas, modas, gustos e ideologías, a veces por vía póstuma. El alemán Rudolf Quehl, albacea del doctor Karl Hoffmann, advertía en una carta escrita en mayo de 1859:

\footnotetext{
${ }^{103}$ Rafael Obregón Loria y George Bowden, La masonería en Cosia Rica (San José 1938).

104 Juan Carlos Solórzano, Populations et systèmes économiques au Guatemala, 1690-1810 (Ph. D. diss., Ecole des Hautes Etudes en Sciences Sociales, París 1981). David J. McCreery, "Debt servitude in rural Guatemala, 1876-1936": Hispanic American Historical Review, 63:4 (November 1983), pp. 735-759.

10s Carolyn Hall, El café y el desarrollo histórico geográfico de Costa Rica (San José 1982), pp. 52-53. En 1935, casi la tercera pare de los beneficiadores era de ascendencia foránea y procesaba el 44 por ciento de la cosecha de café de Costa Rica.
} 
"... me cabe la honra entregar a Ud. [Bruno Carranza, Director de Estudios de Santo Tomás] la Biblioteca que el finado dejo en su testamento á la Universidad ... La intención del difunto, cuya vida estaba dedicada á la salud y al bienestar de sus projimos, no tenia otro objeto que dejar sus libros científicos para la educacion ... de los niños y sin embargo que la mas grande parte esta escrito en aleman, el creyo que con el tiempo si van y vuelven mas hijos de la Republica para continuar en su educacion esencial en Alemania, podrían tener todavía alguna utilidad"106.

La colección del doctor se componía de 92 títulos en 148 volúmenes: en su mayoría, se trataba de obras de medicina y de ciencias naturales, escritas casi todas en alemán. El difunto, sin embargo, poseía varios textos en español, francés, italiano e inglés; entre otros, destacaba un selecto cuerpo de libros: A popular treatise on venereal diseases de Hollik, Historia universal de Becker, The history of England de Macaulay, The poems of Ossian de Macpherson, Das Wesen des Christentums de Feuerbach, Escenas matritenses de Mesonero Romanos y David Copperfield de Dickens.

El cambio cultural, evidente tras 1850 , se caracterizó por un espacio, cada vez más amplio, para las actividades intelectuales, y por una secularización social creciente, ostensible en el caso de los libros. La cultura profana, que se edificó con el decisivo aporte de los extranjeros, fue esencial para el despliegue ulterior de cuadros profesionales. Esta intelligentsia, una minoría con el suficiente poder político ${ }^{107}$, emprendió, 25 años después de que "El Album" editara el catálogo de su librería, una serie de Reformas Liberales ${ }^{108}$ y la construcción oficial de la nacionalidad costarricense ${ }^{109}$.

\section{RESUMEN}

La capitalización del agro en el Valle Central de Costa Rica, cuyo eje fue el cultivo del café, supuso decisivas transformaciones económicas y' sociales después de 1830: privatización de la tierra, expansión del

\footnotetext{
106 ANCR, E, exp. 918 (1859), f. 1.

in Eric Hobsbawm, Nations and nationalism since 1780. Programme, myth, reality (Cambridge 1991), p. 60.

108 Orlando Salazar, El apogeo de la República liberal en Costa Rica (1870-1914) (১an José 1990).

109 Steven Palmer, A liberal discipline. Inventing nations in Guatemala and Cossa Rica (1870-1900) (Ph. D. diss., Columbia University, 1990). 
crédito, auge del comercio exterior y alza en la compra y venta de fuerza de trabajo. El desarrollo de una economía nacional y del Estado fue el trasfondo de un amplio cambio cultural, que empezó a modificar los antiguos patrones de vivienda, consumo, diversión y vida cotidiana, un proceso del que no se exceptuó la cultura libresca.

A fines de la colonia, la circulación de libros en el Valle Central era muy limitada; aunque en las bibliotecas de los sectores más acaudalados figuraban algunas obras selectas (de Derecho, Filosofía, Historia), en lo esencial prevalecían las de carácter devoto, principalmente catecismos, cartillas y novenas. Esta situación comenzó a variar luego de la independencia (1821), cuando una creciente importación de textos se aunó con su producción local, gracias a la introducción de la imprenta (1830).

En este marco, si bien campesinos y artesanos siguieron fieles a un cuerpo de obras tradicionales, de tipo religioso o escolar, la emergente burguesía agroexportadora, asentada en los cascos urbanos de las poblaciones principales (sobre todo de San José, capital del país), empezó a leer las obras de Robertson y Smith, Byron y Sue. Esta europeización de sus gustos literarios fue estimulada por la inmigración de comerciantes y artesanos europeos, quienes contribuyeron a profundizar el proceso de cambio cultural.

\section{ZUSAMMENFASSUNG}

Im zentralen Hochtal von Costa Rica setzte die gewinnbringende Nutzung des Ackerlandes, in deren Mittelpunkt der Kaffeeanbau stand, nach 1830 entscheidende wirtschaftliche und soziale Wandlungen voraus: Privatisierung des Bodens, Kreditausweitung, Aufschwung des Außenhandels und die Expansion des Arbeitsmarktes. Die Entwicklung einer Nationalökonomie sowie des Staates bildeten den Hintergrund für einen weitreichenden kulturellen Wandlungsproze $B$, in dessen Verlauf sich in den Bereichen des Wohnens, Konsums, der Unterhaltung sowie des täglichen Lebens überkommene Verhaltensmuster zu verändern begannen und von dem auch die Buchkultur nicht unberührt blieb.

Zum Ende der Kolonialzeit kursierte im zentralen Hochtal nur eine sehr begrenzte Anzahl von Büchern. Obwohl in den Bibliotheken der begüterten Schichten einige erlesene (juristische, philosophische, historische) Werke vorkamen, überwogen im wesentlichen diejenigen 
geistlichen Charakters, wie vor allem Katechismen, fromme Fibeln und Novenenbücher. Dies begann sich nach der Unabhängigkeit (1821) zu ändern, als der zunehmende Import von Texten sich mit der - durch die Éinführung des Buchdrucks (1830) ermöglichten - lokalen Produktion verband.

So begann, während Bauern und Handwerker weiterhin einem traditionellen Korpus von religiösen oder Unterrichtswerken verhaftet blieben, das aufstrebende, im Export von Agrarprodukten engagierte Bürgertum, das in den städtischen Zentren der wichtigsten Siedlungsschwerpunkte (vor allem der Landeshauptstadt San José) konzentriert war, die Werke von Robertson, Smith, Byron und Sue zu lesen. Diese Europäisierung seines literarischen Geschmacks wurde durch die Einwanderung europäischer Kaufleute und Handwerker angeregt, die zur Vertiefung des kulturellen Wandels beitrugen. 
